\title{
La precaria viabilidad de determinadas concesiones de autopistas de peaje en España. Lecciones estructurales para el modelo de colaboración público-privada y una propuesta de solución coyuntural
}

\author{
Joan Ridao Martín \\ Universidad de Barcelona \\ Alfons García Martínez
}

Economista

SUMARIO: I. INTRODUCGIÓN. II. LAS AUTOPISTAS ESTATALES DE PEAJE ADJUDICADAS EN EL PERIODO 1998-2004. III. ALGUNAS ALTERACIONES DEL EQUILIBRIO ECONÓMICO EN LAS AUTOPISTAS DE PEAJE ANALIZADAS. IV. EL IMPACTO DE LA REGESIÓN ECONOMICA DE 2008 SOBRE LA DEMANDA DE USO DE LAS AUTOPISTAS DE PEAJE. V. LAS DESVIACIONES DE LA DEMANDA DE USO RESPECTO A LAS ESTIMACIONES INICIALES DEL ADJUDICATARIO. VI. EL PROBLEMA CREADO AL ESTADO POR LAS CONCESIONES DEFICITARIAS Y SUS INTENTOS DE SOLUCIÓN. VII. DEFICIENCIAS EN LA TRANSPOSICIÓN ESPAÑOLA DE ALGUNOS PRINCIPIOS VERTEBRADORES DE LA COLABORACIÓN PÚBLICO-PRIVADA. 1. El concepto de riesgo y ventura. 2. La preservación del equilibrio económico. VIII. ALGUNAS IDEAS PARA UN FUTURO VIABLE DEL SISTEMA CONCESIONAL Y LA GOLABORACIÓN PÚBLICO-PRIVADA EN ESPAÑA. 1. Una propuesta de solución concreta a las autopistas de peaje adjudicadas a partir de 1998. 2. Reformas estructurales pendientes en el sistema concesional español. IX. CONCLUSIONES

RESUMEN:

El fracaso de la viabilidad económica de las autopistas radiales de Madrid y algunas de las otras concesiones de autopistas de peaje adjudicadas a partir de 1998 ha creado un serio reto para la Administración del Estado, que debe en- 
contrar una solución en el marco de una severa restricción del déficit público y, a la vez, preservar la confianza futura de los inversores en este tipo de proyectos en España y garantizar la continuidad de la prestación del servicio público que ofrecen las infraestructuras subyacentes. Un análisis de las causas reales que han llevado a la quiebra a estas concesiones permite dibujar con claridad algunas de las deficiencias estructurales del sistema concesional en España. Sobre estos dos aspectos, la solución concreta y la reforma estructural, el artículo formula algunas propuestas específicas.

\section{PALABRAS CLAVE:}

Colaboración público-privada, concesiones públicas, autopistas de peaje, equilibrio económico, demanda de uso de autopistas de peaje, renegociaciones en concesiones.

\section{ABSTRACT:}

The failure of the economic viability of the radial highways of Madrid and some of the other toll road concessions awarded since 1998 has created a serious challenge for the administration of the State, who must find a solution in the context of a severe restriction of the public deficit and simultaneously preserve the future confidence of investors in this type of projects in Spain and ensure the continuity of public service provision offered by underlying infrastructure. An analysis of the real causes that led to the bankruptcy of these concessions can clearly draw some of the structural weaknesses of the concession system in Spain. On these two issues, concrete solutions and structural reform, this article makes some specific proposals.

\section{KEYWORDS:}

Public-Private Partnerships, public concessions, toll roads, economic equilibrium, demand for using toll roads, renegotiations in concessions.

\section{INTRODUCGIÓN}

En septiembre de 2012, Autopista Madrid Sur, Concesionaria Española SA, sociedad adjudicataria de la R-4 (autopista de peaje Madrid-Ocaña), presentó la solicitud de concurso de acreedores; unos días antes, Accesos de Madrid, Concesionaria Española SA, empresa concesionaria de la R-3 (Madrid-Arganda) y la R5 (Madrid-Navalcarnero), solicitó por su parte el preconcurso de acreedores y un año después lo haría Henarsa, concesionaria de la R-2. Las concesiones gestionadas por estas empresas, popularmente conocidas como radiales de Madrid, forman parte de un conjunto de autopistas de peaje adjudicadas en el periodo 19982004, algunas de las cuales se han visto afectadas por diversas problemáticas que, 
finalmente, han comprometido seriamente su viabilidad económica. A este grupo pertenecen también las sociedades concesionarias de las autopistas estatales de peaje AP-41 (Madrid-Toledo) y AP-7 Cartagena-Vera (Aucosta) que solicitaron el concurso de acreedores en mayo de 2012 y febrero de 2013, respectivamente.

A menudo, se ha descrito el proceso mencionado como una desafortunada confluencia de diversas circunstancias exógenas adversas, que encarecieron la construcción de las infrasestructuras, y la coincidencia de su puesta en servicio con los primeros años de la recesión económica, que restringió su demanda de uso. Sin embargo, como intentaremos exponer en este artículo, las razones principales que han conducido al colapso económico de las concesiones mencionadas hay que buscarlas, sobretodo, en la selección de unas ofertas iniciales muy enmarcadas en vicios consuetudinarios de la práctica concesional española. En esencia, el planteamiento subyacente de las mismas, que no es exclusivo de las adjudicaciones del periodo 1998-2004, ni siquiera de la práctica concesional española, era que la Administración concedente no dejaría "caer" las concesiones adjudicadas y que los defectos de rentabilidad financiera contenidos en la planificación económica inicial de las explotaciones serían corregidos mediante la renegociación o renegociaciones posteriores entre el poder público concedente y las sociedades concesionarias. Sin embargo, en el caso de las radiales de Madrid y los otros casos examinados, este esquema se complicó por diversas razones.

Por un lado, la Administración estatal, gobernada desde 2004 por un partido distinto al que había auspiciado las concesiones, al principio fue renuente a abordar la renegociación de las concesiones y cuando, finalmente, esto se hizo inevitable para intentar evitar el colapso económico de las mismas, la crisis de la deuda soberana y la caída en picado de los ingresos tributarios anuló su margen de maniobra presupuestario para ofrecer soluciones efectivas al deteriorado equilibrio económico de las concesiones.

La mayor parte del debate público de los últimos años sobre las concesiones de autopistas de peaje en el Estado español ha estado centrada en la equidad de la distribución territorial de las mismas, un enfoque legítimo, pero que ha dejado muy poco espacio al debate sobre la eficiencia de las concesiones y, en general, del resto de fórmulas jurídicas de financiación privada de infraestructuras de interés público. Y, en las pocas ocasiones en que éste ha aparecido, habitualmente se ha realizado desde posiciones muy polarizadas, que centraban el debate sobre el carácter de prebenda para determinados grupos empresariales y financieros del uso de la fórmula concesional, lo que ha oscurecido ostensiblemente un desarrollo técnico y racional del mismo. Lógicamente, este estado de opinión general no ha facilitado, tampoco, la resolución del problema creado a las Administraciones públicas por las concesiones de autopistas en dificultades económicas. 
Finalmente, el profundo proceso de reestructuración que ha experimentado el sistema financiero español desde 2009, principalmente en el sector de las cajas de ahorro, ha tenido también importantes consecuencias sobre los instrumentos de financiación de estas concesiones, en España fundamentalmente vinculados al crédito bancario.

En este artículo expondremos algunos de los factores que han incidido en la inviabilidad financiera del grupo de concesiones de referencia. También, discutiremos, con un cierto detalle, el alcance real de la influencia del ciclo económico sobre el déficit de explotación de las mismas. Con estos elementos y la plasmación jurídica de los elementos nucleares del sistema concesional español dibujaremos un esquema de la problemática que se genera para el Gobierno del Estado (la administración concedente) a partir de la quiebra de las concesiones. Concluiremos enunciando algunos criterios para la solución específica de las autopistas radiales y las otras concesiones problemáticas, así como con una serie de recomendaciones generales de reforma de la legislación española pertinente, con el objetivo de mejorar la equidad y la eficiencia de la asignación de riesgos y retribuciones, válidas no sólo para el sistema concesional en sentido estricto, sino también para las diversas fórmulas de colaboración público-privada en la provisión de infraestructuras y servicios públicos.

\section{LAS AUTOPISTAS ESTATALES DE PEAJE ADJUDICADAS EN EL PERIODO 1998-2004}

La Red Estatal de Autopistas de Peaje (REAP), integrada por el conjunto de autopistas de peaje en concesión cuya titularidad corresponde al Estado central ${ }^{1}$, tiene sus orígenes en 1960 con la adjudicación del túnel de Guadarrama (hoy integrado en la AP6 Villalba-Villacastín-Adanero) y en la actualidad agrupa 32 concesiones y unos $2.800 \mathrm{Km}$ de vías. Esta red ha sido desplegada de forma discontinua en el tiempo. Como señalan BAEZA Y VASSALlo (2011), su desarrollo ha tenido dos períodos fundamentales: el periodo 1967-1975 (Programa de Autopistas Nacionales Españolas, 15 concesiones y unos $1.800 \mathrm{Km}$ de vías) y el período $1998-$ 2004 (Programa de Autopistas de Peaje, 15 concesiones más y unos $1.000 \mathrm{Km}$ de trazado). En el primero de los periodos citados se incorporaron los fundamentos del sistema de concesiones de peaje al ordenamiento Estado español, una fórmula de

\footnotetext{
${ }^{1}$ Este conjunto ha tenido, con el tiempo, un perímetro variable. No sólo por la adición de nuevas concesiones, sino también por la segregación de algunas que inicialmente formaron parte: es el caso del puente sobre la bahía de Cádiz (liberado de peaje en 1982), el túnel del Cadí (traspasado a la Generalitat de Catalunya), la A-19 Montgat-Malgrat y la A-17 Barcelona-Montmeló (incluido en la concesión Barcelona-La Junquera), segregados ambos en 1995, la autopista Bilbao-Behobia (segregada en 2000) o el tramo León-Onzonilla de la AP-66 (segregado en 2003).
} 
financiación de las vías de alta capacidad que ya era común en el desarrollo de las redes de otros países de la Europa mediterránea, como Francia e Italia, durante la segunda mitad del siglo XX (BEL y FAGEDA, 2005). Por su parte, las concesiones incluidas en el Programa de 1997 se planificaron en un contexto absolutamente distinto. Gran parte de los proyectos provenían del Plan Director de Infraestructuras (1993-2007), si bien clasificados allí como autovías, es decir, gratuitas para el usuario, pero con el cambio de signo político en el Gobierno estatal se creyó oportuno proceder a una modificación del paradigma en la financiación de este tipo de proyectos de inversión pública, integrando una substancial implicación del sector privado, retribuida fundamentalmente con pagos directos de los usuarios de las infraestructuras.

Mediante la Orden del Ministerio de Fomento de 26 de mayo de 1997 se declararon "urgentes y de excepcional interés público" algunos de los proyectos de autopistas de peaje incluidos en el Programa, con el fin de acortar los plazos de su planificación y licitación, entre estos proyectos se encontraban las autopistas radiales de Madrid (las R-2, R-3, R-4 y R-5), para las cuales se fundamentaba el carácter de urgencia e interés en la congestión de las vías a las que habían de servir de alternativa y al "crecimiento previsto de las viviendas ocupadas en la periferia madrileña". La citada Orden recogía también la conclusión de la M-50, obra que en diferente partes acabó integrada dentro de las concesiones de autopistas radiales, aunque manteniendo su carácter de autovía.

La Tabla 1 relaciona las concesiones que hemos considerado problemáticas a los efectos de este artículo ${ }^{2}$ y detalla, para cada una, dos características especialmente destacables. En primer lugar, la inclusión en las concesiones de un número considerable de encargos de construcción y explotación de vías gratuitas, funcionalmente conectadas a las concesiones de peaje, que debían ser asumidas por los concesionarios con cargo a los presuntos beneficios de la explotación de estas últimas. Esta práctica, conocida como "financiación cruzada", suele presentarse como un instrumento de reversión parcial de los excedentes de explotación de los peajes al interés público; aunque también puede ser interpretada como una traslación de la financiación de estas obras complementarias al usuario de las vías de peaje. En cualquier caso, su uso implica el desplazamiento íntegro del riesgo de construcción de estas obras públicas al sector privado, adicionalmente al de las

\footnotetext{
${ }^{2}$ El grupo de concesiones que hemos considerado problemáticas en este artículo son las que han sido beneficiarias, simultáneamente, de las ayudas estatales para la financiación de los sobrecostes de expropiación y para la compensación de las desviaciones de las previsiones de demanda de uso de las vías (ver apartado 6). También podrían considerarse problemáticas desde el punto de vista económico-financiero algunas más, como la AP-36 (Ocaña-La Roda) o la AP-53 (Santiago de Compostela-Alto de Santo Domingo).
} 
infraestructuras subyacentes a la concesión propiamente dicha, lo cual ha tenido una cierta relevancia en los casos que analizamos. En segundo lugar, resulta interesante la consignación en el decreto de adjudicación de una cifra máxima en concepto de responsabilidad patrimonial de la Administración, cuyo importe global se sitúa entorno a los 3.000 millones de euros.

La Tabla 2 muestra diversos datos societarios de las concesionarias de cada una de las autopistas consideradas. En general, la distribución del capital social muestra una participación determinante de tres categorías empresariales: entidades de crédito, constructoras y sociedades concesionarias de otras autopistas de peaje (a veces, a través de sociedades participadas).

TABLA 1. Resumen de las principales características de las adjudicaciones de autopistas estatales de peaje problemáticas

\begin{tabular}{|c|c|c|c|}
\hline & $\begin{array}{l}\text { Norma de } \\
\text { Adjudicación }\end{array}$ & $\begin{array}{l}\text { Obras adicionales } \\
\text { incluidas en la } \\
\text { concesión }\end{array}$ & $\begin{array}{l}\text { Responsabilidad } \\
\text { Patrimonial de la } \\
\text { Administración }\end{array}$ \\
\hline $\begin{array}{l}\text { R-2 Madrid - } \\
\text { Guadalajara }\end{array}$ & $\begin{array}{l}\text { REAL } \\
\text { DECRETO } \\
\text { 1834/2000, de } 3 \\
\text { de noviembre }\end{array}$ & $\begin{array}{l}\text { M-50, subtramo desde la } \\
\text { carretera N-II hasta la } \\
\text { carretera N-I. }\end{array}$ & $40,7 \mathrm{M} €$ \\
\hline $\begin{array}{l}\text { R-3 Madrid - } \\
\text { Arganda } \\
\text { R-5 Madrid - } \\
\text { Navalcarnero }\end{array}$ & $\begin{array}{l}\text { REAL } \\
\text { DECRETO } \\
\text { 1515/1999, de } 24 \\
\text { de septiembre }\end{array}$ & $\begin{array}{l}\text { Tramo de la M- } 50 \text { entre la } \\
\text { autopista A- } 6 \text { y la carretera } \\
\text { M- } 409 .\end{array}$ & $638 \mathrm{M} €$ \\
\hline $\begin{array}{l}\text { R-4 Madrid - } \\
\text { Ocaña }\end{array}$ & $\begin{array}{l}\text { REAL } \\
\text { DECRETO } \\
\text { 3540/2000, de } 29 \\
\text { de diciembre }\end{array}$ & $\begin{array}{l}\text { M-50, subtramo desde la } \\
\text { carretera N-IV hasta la } \\
\text { carretera N-II. } \\
\text { Eje sureste, tramo } \\
\text { M-40-M-50. } \\
\text { Prolongación de la conexión } \\
\text { de la carretera N-II con el } \\
\text { distribuidor este. } \\
\text { Actuaciones de mejora en la } \\
\text { M-50, tramo M-409-N-IV. }\end{array}$ & 559,7 M€ \\
\hline
\end{tabular}




\begin{tabular}{|c|c|c|c|}
\hline & $\begin{array}{l}\text { Norma de } \\
\text { Adjudicación }\end{array}$ & $\begin{array}{l}\text { Obras adicionales } \\
\text { incluidas en la } \\
\text { concesión }\end{array}$ & $\begin{array}{l}\text { Responsabilidad } \\
\text { Patrimonial de la } \\
\text { Administración }\end{array}$ \\
\hline $\begin{array}{l}\text { M12 Fje } \\
\text { aeropuerto }\end{array}$ & $\begin{array}{l}\text { REAL DEGRETO } \\
1197 / 2002 \text {, de } 8 \text { de } \\
\text { noviembre }\end{array}$ & $\begin{array}{l}\text { Prolongación y mejoras } \\
\text { del acceso sur a Barajas. } \\
\text { Ampliación a tres carri- } \\
\text { les de la autovía A-10, } \\
\text { entre la conexión con el } \\
\text { eje aeropuerto y el nudo } \\
\text { de Hortaleza. } \\
\text { Conexión aeropuerto-va- } \\
\text { riante N-II. } \\
\text { Vías de servicio sur de } \\
\text { Barajas. }\end{array}$ & 305,5 M€ \\
\hline $\begin{array}{l}\text { AP41 Madrid - } \\
\text { Toledo }\end{array}$ & $\begin{array}{l}\text { REAL DEGRETO } \\
281 / 2004 \text {, de } 13 \text { de } \\
\text { febrero }\end{array}$ & $\begin{array}{l}\text { Autovía libre de peaje A- } \\
40 \text { de Castilla-La Man- } \\
\text { cha, tramo: circunvala- } \\
\text { ción norte de Toledo. }\end{array}$ & 348,9 M€ \\
\hline $\begin{array}{c}\text { AP-7 Cartagena } \\
\text { - Vera }\end{array}$ & $\begin{array}{l}\text { REAL DEGRETO } \\
245 / 2004 \text {, de } 6 \text { de } \\
\text { febrero }\end{array}$ & $\begin{array}{l}\text { Construcción, conserva- } \\
\text { ción y explotación de la } \\
\text { autovía libre de peaje pa- } \\
\text { ra los tráficos internos de } \\
\text { circunvalación de Carta- } \\
\text { gena. }\end{array}$ & $526,8 \mathrm{M} €$ \\
\hline $\begin{array}{l}\text { AP-7 Circunva- } \\
\text { lación de Ali- } \\
\text { cante }\end{array}$ & $\begin{array}{l}\text { REAL DEGRETO } \\
\text { 282/2004, de } 13 \text { de } \\
\text { febrero }\end{array}$ & $\begin{array}{l}\text { Construcción, conserva- } \\
\text { ción y explotación de: } \\
\text { - La variante de El Cam- } \\
\text { pello. } \\
\text { - La autovía denominada } \\
\text { Camino de Castilla. } \\
\text {-Tercer carril en la auto- } \\
\text { vía A-7, entre Elche y } \\
\text { Crevillente, } \\
\text { Construcción de: } \\
\text {-Adecuación y reforma } \\
\text { del corredor de Levante } \\
\text { (N-330), tramo: Alicante- } \\
\text { límite de la provincia } \\
\text { con Albacete. } \\
\text { - Diversas vías de acceso } \\
\text { y rondas de Elche }\end{array}$ & 398,6 M€ \\
\hline
\end{tabular}

Fuente: Elaboración propia a partir del texto de los decretos publicado en el BOE y datos Ministerio de Fomento. 
TABLA 2. Sociedades concesionarias de las concesiones problemáticas. Distribución del accionariado. Situación a 31.12.2011

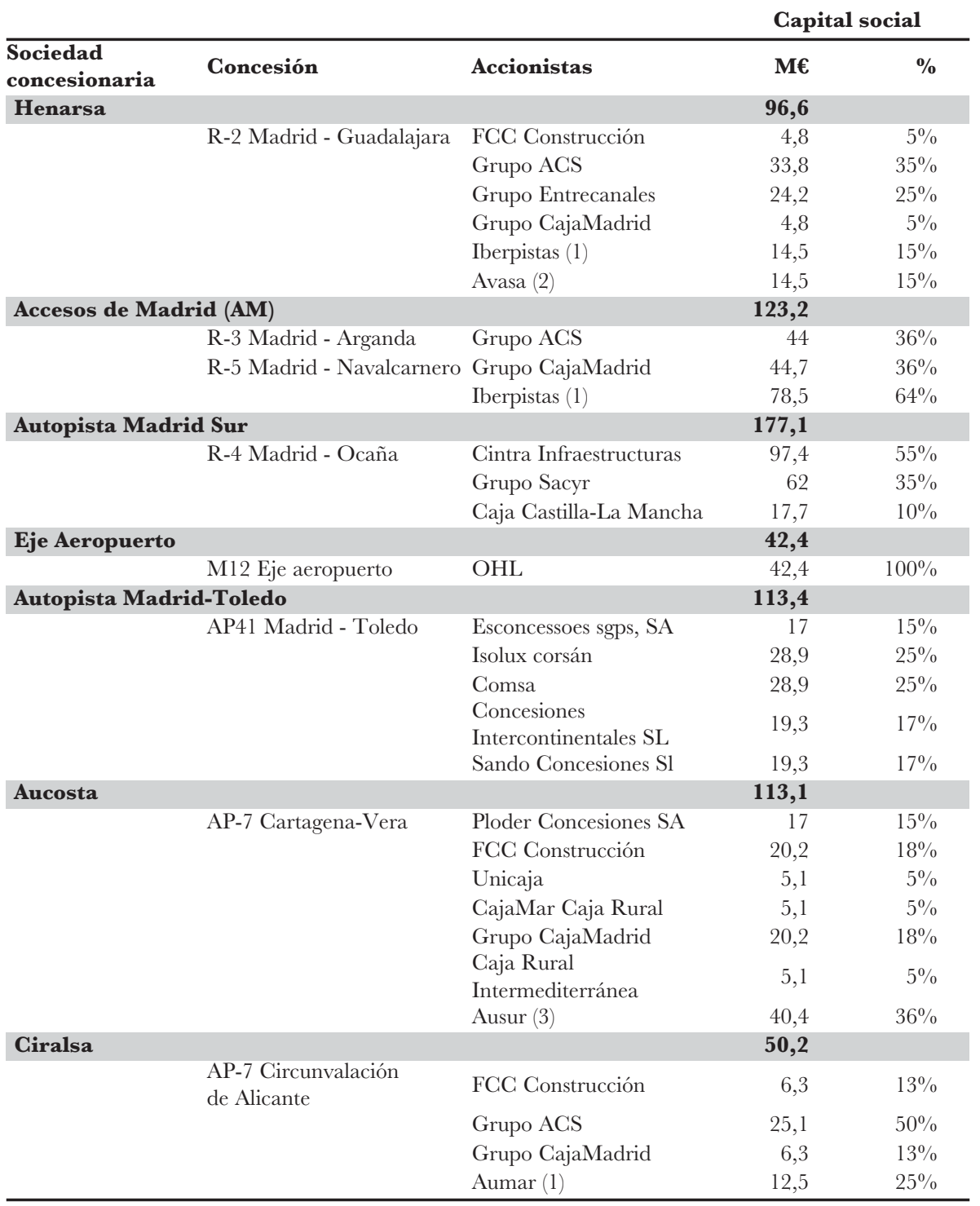

(1) Propiedad al 100\% de Abertis Infraestructuras.

(2) Propiedad al 100\% de Iberpistas (1).

(3) Propiedad de Infucapital (20\%), Ploder Concesiones SA (33\%), Unicaja (14,6\%), CajaMar $(22,1 \%)$ y Caja de Ahorros de Murcia (10\%).

Fuente: Delegación del Gobierno en las Sociedades Concesionarias de Autopistas Nacionales de Peaje. 


\section{ALGUNAS ALTERAGIONES DEL EQUILIBRIO EGONÓ- MICO EN LAS AUTOPISTAS DE PEAJE ANALIZADAS}

Recurriendo al tópico, se podría decir que entorno a la viabilidad económico-financiera del conjunto de concesiones que analizamos aquí se generó un marco global de verdadera "tormenta perfecta", al concurrir una multitud de incidencias que alteraron substancialmente su equilibrio económico, en detrimento de los adjudicatarios. Un ejemplo de afectaciones fue la R-4, que vio su trazado inicial alterado por el hallazgo de los yacimientos paleontológicos de Cerro Batallones (Torrejón de Velasco) y los hallazgos arqueológicos de Mina Casa Montero (Vicálvaro), así como por los planeamientos urbanísticos posteriores a la adjudicación (PAU de Los Cerros y el enlace de la R-3 con la M-50, no previsto en el trazado inicial). Estas contingencias alteraron y encarecieron significativamente su proceso de construcción.

Sin embargo, la incidencia con más impacto económico, en términos generales, ha sido la notable desviación del coste de las expropiaciones determinado por las sentencias judiciales respecto al inicialmente previsto, circunstancia que alteró substancialmente el riesgo constructivo asumido por las concesionarias. El problema arrancó con la doctrina sobre el valor de mercado del suelo como referencia para determinar el valor de las expropiaciones que incorporó la entonces nueva Ley 6/1998, de 13 de abril, sobre Régimen del Suelo y Valoraciones, que sirvió de fundamento para una catarata de demandas de los propietarios expropiados por la construcción de las concesiones de autopistas de peaje, reclamando que el justiprecio aplicado en las expropiaciones, principalmente en casos de suelo no urbanizable o urbanizable no programado, incorporase la valoración de las "expectativas urbanísticas" generadas por las propias infraestructuras. Los tribunales dieron amparo a estas pretensiones de la propiedad, lo que originó un encadenamiento de recursos de las concesionarias que han culminado en diversas sentencias del Tribunal Supremo que, de forma general, han apreciado el derecho de los propietarios.

El impacto cuantitativo de las sentencias judiciales sobre los justiprecios a aplicar en las expropiaciones fue enorme. Teniendo en cuenta, además, que no sólo afectaban a los terrenos afectados propiamente a las autopistas de peaje, sino al conjunto de las concesiones, incluidas las obras de vías sin coste para el usuario, asumidas dentro de la "financiación cruzada" que hemos visto antes (caso, por ejemplo, de diversos tramos de la M-50). Se estima que, para el conjunto de concesiones afectadas, el coste final de las expropiaciones se multiplicó por más de siete respecto a las estimaciones en pliego.

Un ejemplo de concesión particularmente "castigada" por la acumulación de circunstancias adicionales que incidían muy negativamente sobre su equilibrio 
económico es la autopista de peaje Madrid-Toledo (AP-41). La concesionaria de esta vía presentó un recurso contencioso por lo que consideraba dos hechos que perjudicaban gravemente la viabilidad económica de la explotación y solicitaba el restablecimiento del equilibrio económico de la misma mediante sendas indemnizaciones. En primer lugar, la concesionaria manifestaba que el desdoblamiento de la carretera autonómica M-407 (en servicio desde mayo de 2007, cuando la autopista de peaje abrió al tráfico en diciembre de 2006), autovía de alta capacidad que se financia con el llamado peaje en la sombra y, por tanto, no sometida a pago por parte del usuario, provocó que la AP-41 no absorbiese el tráfico del Sur de Madrid, de acuerdo con la previsión inicial, pues le había privado de tráfico en sus tramos iniciales y, además, ha descongestionada la A-42 (otra vía alternativa). En segundo lugar, la concesionaria alegaba que el proyecto original contemplaba una vía de peaje Madrid-Andalucía, sin necesidad de atravesar el Puerto de Despeñaperros (acortando el trayecto en $70 \mathrm{Km}$ ), de la cual el tramo hasta Toledo era la primera fase; sin embargo, el trazado desde Toledo a Córdoba fue descartado por el Ministerio de Fomento a partir de la declaración negativa de impacto ambiental del proyecto de trazado de la nueva autopista (mayo de 2007), por su afectación a espacios de la Red Natura 2000. La concesionaria sostenía que ambos hechos (el desdoblamiento de la M-407 y la declaración negativa de impacto ambiental sobre el proyecto de autopista Toledo-Ciudad Real-Córdoba) eran imprevisibles en el momento en que presentó su oferta e impedían dos de las funciones principales asignadas a la AP-41: constituir el primer tramo de un nuevo corredor a Andalucía y servir de alternativa rápida y eficaz para unir Toledo y los municipios del Sur de la Comunidad de Madrid con la capital, atendiendo así al tráfico de esa parte del área metropolitana.

El Tribunal Supremo (TS) (STS 3125/2011 de 16 de mayo) desestimó la primera de las razones alegadas por la concesionaria con la argumentación de que la mejora de las infraestructuras del transporte y, en particular, las carreteras por parte de las Administraciones no puede considerarse un "hecho extraordinario e imprevisible que deba quedar fuera del riesgo y ventura del contratista" ${ }^{\text {. En }}$

\footnotetext{
${ }^{3}$ No deja de sorprender esta argumentación de la sentencia ya que, en otros contextos legales, la construcción de una infraestructura alternativa de uso gratuito se considera, claramente, una alteración grave del equilibrio económico de una concesión. Así sucede en EUA, por ejemplo, con el contrato de arriendo de la operación y mantenimiento de la Indiana Toll Road (ITR), por un periodo de 75 años, a un consorcio formado por la operadora española Cintra y Macquarie Investment Holdings, a cambio del producto de los peajes pagados por los usarios, lo que supuso para el gobierno del Estado de Indiana unos ingresos de 3.850 millones de US\$, la mayor privatización de este tipo en EUA. El contrato de arriendo contiene, entre otras garantías, una cláusula que impide al Estado, durante 55 años, ampliar la capacidad de las autovías cuyo trazado se sitúe, durante un recorrido mínimo entorno a los $15 \mathrm{Km}$, por debajo de una determinada distancia de la autopista de peaje.
} 
cambio, el TS sí estimó parcialmente el segundo de los hechos descritos, por entender que "la entrada en servicio de la nueva autopista tenía un peso fundamental en el planteamiento de la AP-41, pese a no hacerse referencia a ella en las cláusulas del contrato entre AMT y la Administración (...), desde el momento en que las partes habían asumido que aquella fue concebida como la primera parte del nuevo acceso a y desde Andalucía. Por tanto, siendo éste un presupuesto esencial en la concepción de la AP-41". Sin embargo, el TS no consideró suficientemente fundamentadas las valoraciones efectuadas por la concesionaria de las implicaciones económicas del hecho (algo más de $420 \mathrm{M€}$ ), por lo cual se limitó a "reconocer el derecho de la recurrente a que se restablezca el equilibrio económico y financiero de su concesión en función del impacto producido por esta circunstancia. Derecho que se habrá de concretar una vez determinado el monto de tales menoscabos en el procedimiento de restablecimiento de dicho equilibrio que deberá incoar y llevar a término la Administración General del Estado".

\section{EL IMPACTO DE LA REGESIÓN EGONÓMICA DE 2008 SOBRE LA DEMANDA DE USO DE LAS AUTOPISTAS DE PEAJE}

Sobre la demanda de uso de las vías de peaje influye una considerable diversidad de factores. Sin ánimo de ser exhaustivos, entre ellos cabe citar la configuración funcional del territorio al cual debe dar servicio la vía en cuestión, la presencia de alternativas operativas de menor coste para el usuario o el nivel de renda disponible del territorio en relación a las tarifas que el usuario debe abonar por utilizar la vía. Otro factor con una incidencia determinante en la demanda de uso de las vías de peaje es el ciclo económico.

Para constatar este hecho en el caso español, hemos seleccionado una muestra de las concesiones estatales más antiguas ${ }^{4}$ y hemos relacionado la variación de la demanda de uso, indicada por la intensidad media diaria (IMD) de vehícu-

\footnotetext{
${ }^{4}$ La muestra de concesiones utilizada (todas adjudicadas entre 1967 y 1975) está integrada por las autopistas estatales de peaje AP1 BURGOS-ARMIÑON, AP2 ZARAGOZA MEDITERRÁNEO, AP4 SEVILLA-CÁDIZ, AP66 LEÓN-GAMPOMANES, AP68 BILBAO-ZARAGOZA, AP7 BARCELONATARRAGONA, AP7 MONTMELÓ-LA JUNQUERA, AP7 TARRAGONA-VALENCIA, AP9 FERROL-PORTUGAL. Los motivos de la elección han sido varios. En primer lugar, estas concesiones más antiguas presentan unos flujos de demanda muy consolidados, lo cual permite aislar relativamente los efectos del ciclo económico de los derivados de otras variables. En segundo lugar, la muestra ofrece una representación territorial bastante plural del Estado. Y, finalmente, la antigüedad de las concesiones permite disponer de una serie amplia de datos que facilita un análisis de ciclo largo.
} 
los que circulan ${ }^{5}$, con las oscilaciones del crecimiento del PIB $^{6}$. Con estas cifras hemos realizado un análisis de regresión simple, recogido en el Gráfico 1, que sugiere una clara vinculación entre la variación de la demanda de uso y la de creación de riqueza (el PIB $)^{7}$. En el caso de los vehículos pesados, cuyo uso de las vías se haya más estrechamente ligado a la actividad empresarial, el gráfico indica una mayor reacción a los cambios del ciclo económico.

La explicación de este comportamiento es conocida. En épocas de crecimiento de la renta disminuye la resistencia de los usuarios a pagar por utilizar las vías de peaje y disponer, así, del mayor nivel de servicio y comodidad que proporcionan. Al mismo tiempo, los volúmenes generales de tráfico por carretera aumentan, lo cual incrementa la saturación de algunas vías gratuitas alternativa y favorece la opción del peaje. En una coyuntura de recesión económica, estos mecanismos operan en sentido inverso. Hay que destacar que, en este razonamiento, la presencia de vías de alta capacidad alternativas, y sobretodo su grado de saturación (CANTOS y ÁlvaREz, 2009), actúan como un elemento muy relevante de competencia por la misma demanda, favoreciendo especialmente el desplazamiento de usuarios entre vías de peaje y vías de uso gratuito en función de la coyuntura económica.

\footnotetext{
${ }^{5}$ Los valores de base de la IMD de cada autopista que hemos utilizado son los que ofrece, como media mensual desde enero de 1990, el Ministerio de Fomento (http://www.fomento.gob.es/BE/), aunque aquí hemos utilizado las cifras a partir de 1999 hasta el primer trimestre de 2013, por homogeneidad con la serie del PIB. Las estadísticas del Ministerio ofrecen la IMD general de vehículos y, separadamente, la de vehículos pesados. Para homogeneizarlos con los datos del PIB de la Contabilidad Nacional Trimestral, hemos transformado estos valores en trimestrales simplemente aplicando la media aritmética de los datos mensuales. Finalmente, para integrar los datos de las diversas concesiones de la muestra en una única serie, hemos procedido a calcular mensualmente la IMD teórica (que actuaría, más bien, como un índice sintético) de una única autopista cuyos segmentos serían el conjunto de concesiones de la muestra. Hay que tener en cuenta que la metodología del Ministerio calcula la IMD "dividiendo los vehículos-kilómetro entre los kilómetros-día en servicio de la autopista. Los vehículos-kilómetros se definen como la magnitud que indica la suma total de los kilómetros recorridos por todos los vehículos que utilizan la autopista correspondiente en un periodo de tiempo".

${ }^{6}$ Los datos del PIB a precios de mercado utilizados son, como hemos dicho, los que proporciona la Contabilidad Nacional Trimestral de España, elaborada por el INE (http://www.ine.es/jaxi/menu.do?ty$\mathrm{pe}=$ pcaxis\&path $=\% 2 \mathrm{Ft} 35 \% 2 \mathrm{Fp} 009 \&$ file $=$ inebase $\& \mathrm{~L}=0)$. En concreto hemos utilizado el valor del PIB trimestral corregido de estacionalidad y calendario, en euros corrientes, calculado con la base 2008, que ofrece datos desde el primer trimestre de 2000.

${ }^{7}$ Practicando el mismo análisis a la IMD de vehículos pesados, cuyo uso de las vías se haya más estrechamente ligado a la actividad empresarial, es encuentra una mayor reacción a los cambios del ciclo económico y un nivel de correlación más estrecho entre las variables.
} 
Gráfico 1. Variaciones interanuales del tráfico (IMD-General) en autopistas de peaje y del PIBpm (2000-2013) Ajuste por regresión.

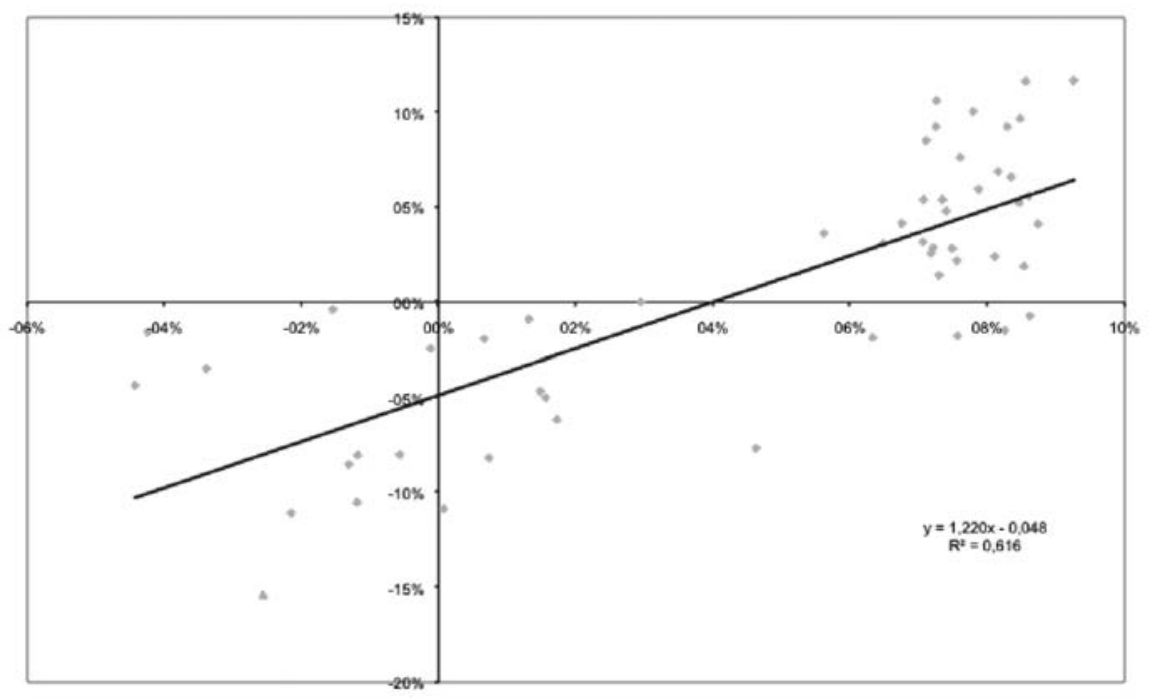

Fuente: Elaboración propia con datos del Ministerio de Fomento y del INE.

Hemos realizado, también, un ejercicio análogo al descrito en la nota 5 para el grupo de vías problemáticas. Las primeras concesiones de nuestro grupo de autopistas problemáticas que entraron en operación no lo hicieron hasta el último trimestre de 2003. Por esta razón, al analizar los datos de demanda de uso de estas vías se debe añadir la volatilidad propia de los periodos iniciales de las concesiones (efecto ramp-up) a los efectos inducidos por la coyuntura de recesión. Por otro lado, hay que tener presente que el trazado de la práctica totalidad de las autopistas integradas en este grupo discurre en un entorno metropolitano, de elevada densidad de tránsito y notable oferta alternativa de vías de uso gratuito para el usuario, algunas de gran capacidad. Los resultados de este análisis se recogen en el Gráfico 2, en el cual se observa que, una vez pasado el periodo inicial (a partir de la segunda mitad de 2008, aproximadamente) el perfil de la curva de variación de la demanda de uso de las vías de peaje incluidas en la muestra es bastante coherente con el comportamiento de la muestra de autopistas "maduras", aunque con una mayor sensibilidad a la contracción del PIB. 
Gráfico 2. Evolución del PIBpm y del tráfico en autopistas de peaje (20002013). Muestra de autopistas maduras (M1) y autopistas problemáticas (M2)

\section{Variación interanual de los datos trimestrales}

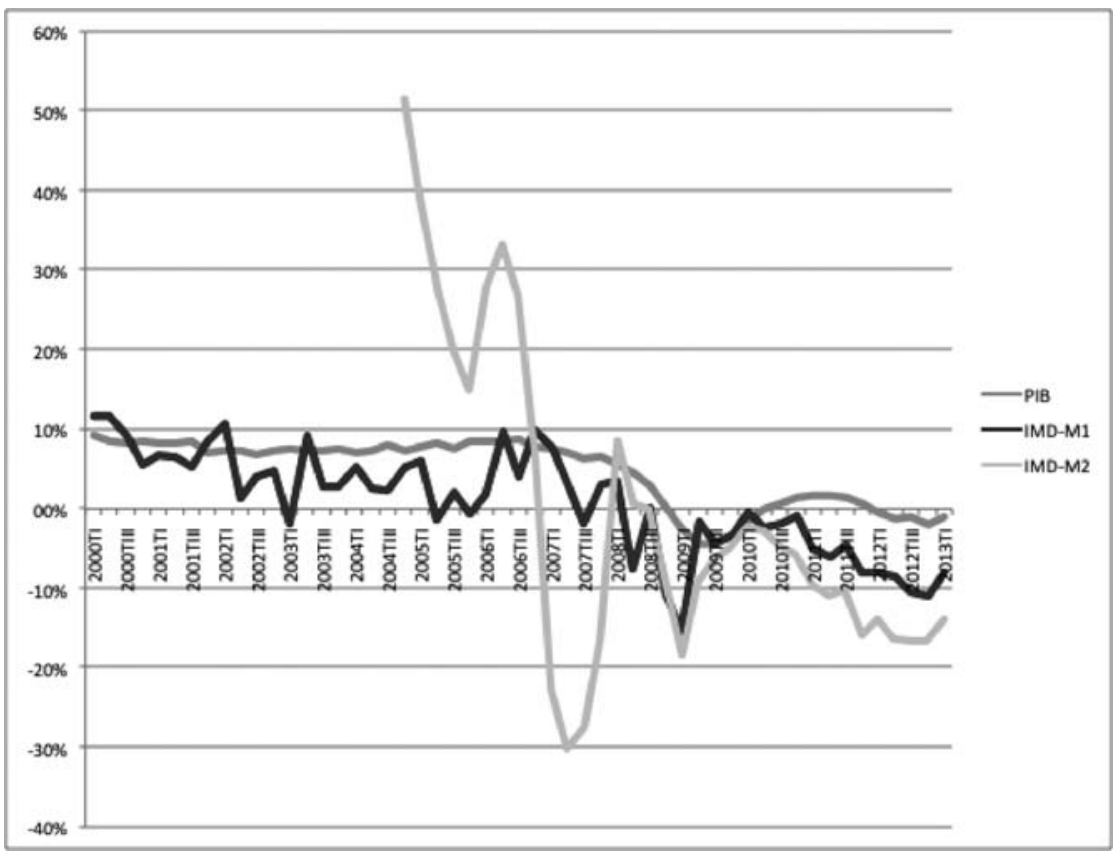

Fuente: Elaboración propia con datos del Ministerio de Fomento y del INE.

¿En qué medida la baja rentabilidad de las concesiones analizadas ha venido determinada por esta sensibilidad de su demanda de uso a la recesión económica? Es indudable que la caída de los niveles de frecuentación y, por tanto, de los ingresos generados por la operación de las autopistas consideradas, han sido más severos en los casos de estas vías de peaje de nueva creación. La IMD agregada en la muestra de autopistas de peaje "maduras" había caído, a principios de 2013, un 32\% en relación al máximo histórico del primer trimestre de 2008, mientras que en el conjunto de autopistas que analizamo, la reducción fue superior al 45\% en el mismo periodo. Las variaciones de uso de las vías son, sin embargo, una parte de la cuestión. La otra parte se recoge en la Tabla 3, que relaciona el ingreso por kilometro de cada una de las vías consideradas con el valor medio anual del conjunto de la red estatal. El resultado manifiesta una notable 
inferioridad de rentabilidad de nuestras autopistas, que en algunos casos (Cartagena-Vera, Madrid-Toledo) se situa por debajo del 15\% de la media del conjunto de autopistas estatales de peaje. Sin embargo, las tarifas unitarias de estas concesiones (en términos de euros de tarifa por vehículo y kilómetro) se situaban en niveles medios del conjunto de autopistas estatales de peaje ${ }^{8}$. Es decir, aunque las reducciones de uso de la autopistas objeto de nuestro análisis, durante la recesión económica, han tenido una intensidad superior a las de las concesiones más consolidadas, los diferenciales de ingresos unitarios con respecto a los ingresos medios indican significativas deficiencias en el proceso de establecer el nivel de precios de los peajes en relación a los flujos de tráfico esperables, aún considerando el efecto ramp-up o o la competencia imprevista (como en el caso de la AP-41).

TABLA 3. Recaudación unitaria $(€ / \mathrm{Km})$ en las autopistas estatales de peaje problemáticas, en $\%$ de la media del total de la red (= $100 \%)$.

Datos a partir del primer año completo de funcionamiento

\begin{tabular}{|c|c|c|c|c|c|c|}
\hline & 2006 & 2007 & 2008 & 2009 & 2010 & 2011 \\
\hline R-2 Madrid - Guadalajara & $55,3 \%$ & $60,7 \%$ & $60,3 \%$ & $63,0 \%$ & $64,7 \%$ & $57,9 \%$ \\
\hline R-3 Madrid - Arganda & $55,7 \%$ & $59,0 \%$ & $57,4 \%$ & $60,5 \%$ & $60,7 \%$ & $62,9 \%$ \\
\hline R-5 Madrid - Navalcarnero & $45,7 \%$ & $59,6 \%$ & $57,9 \%$ & $58,1 \%$ & $60,8 \%$ & $65,4 \%$ \\
\hline R-4 Madrid - Ocaña & $54,2 \%$ & $75,1 \%$ & $73,1 \%$ & $63,4 \%$ & $60,0 \%$ & $53,5 \%$ \\
\hline M12 Eje aeropuerto & $83,7 \%$ & $400,6 \%$ & $109,4 \%$ & $91,7 \%$ & $89,2 \%$ & $87,3 \%$ \\
\hline AP41 Madrid - Toledo & & $15,2 \%$ & $11,6 \%$ & $10,9 \%$ & $10,0 \%$ & $8,5 \%$ \\
\hline AP-7 Cartagena - Vera & & & $15,1 \%$ & $13,4 \%$ & $13,2 \%$ & $13,1 \%$ \\
\hline AP-7 Circunvalación de Alicante & & & $39,6 \%$ & $37,1 \%$ & $34,4 \%$ & $32,7 \%$ \\
\hline
\end{tabular}

\footnotetext{
${ }^{8}$ Según las cifras publicadas por la Secretaria de Estado de Infraestructuras, Transportes y VIVIENDA (2012). Cabe citar en relació a esto la excepción de la M-12, en un efecto derivado de que esta vía contaba con una tarifa establecida, en el decreto de concesión, por barrera de peaje y no en $€ / \mathrm{Km}$.
} 


\section{LAS DESVIACIONES DE LA DEMANDA DE USO RESPEG- TO A LAS ESTIMAGIONES INICIALES DEL ADJUDICATA- RIO}

$\mathrm{Al}$ comparar las cifras reales de tráfico respecto a las previsiones iniciales contenidas en los planes económicos de cada concesión, BAEZA Y VASSALLO (2011) muestran, para la mayoría de las concesiones consideradas aquí como problemáticas, unas cifras de tráfico real un 50-60\% inferiores a las estimaciones durante los cinco primeros años de operación, con algunos datos extremos de desviaciones negativas entorno al $80 \%$. Estas cifras son bastantes consistentes con las que hemos expuesto anteriormente respecto a los ingresos por kilómetro en relación a la media estatal. Aunque, como hemos dicho, podría existir la tentación de atribuir en exclusiva la dimensión de estas desviaciones a la práctica coincidencia de su puesta en servicio con el inicio de la recesión económica, los autores mencionados constatan también desviaciones similares para un buen número de las concesiones que entraron en servicio durante los años 70 del siglo XX, lo cual les permite afirmar que "el modelo de concesión español adolece de un grave problema: los estudios de tráfico se incumplen desde hace cuarenta años" (p. 54).

La persistencia en el tiempo y la dimensión de las sobreestimaciones de los volúmenes de tráfico en las ofertas ganadoras de las adjudicaciones no deja de ser un hecho sorprendente que tiene, además, profundas implicaciones en el devenir de las concesiones. Aunque algunas veces se ha señalado que los procedimientos estadísticos aplicados por la Administración española para proporcionar la información de base para las estimaciones de flujos de tránsito adolecen de algunos defectos técnicos, llama la atención, en primer lugar, que la dilatada experiencia en el desarrollo de proyectos de autopistas de peaje en España no haya comportado mejoras significativas en este aspecto. En segundo lugar, la demanda de uso de estas infraestructuras es objeto de una doble estimación: la de la Administración, en el preceptivo estudio de viabilidad de toda concesión de obra público ${ }^{9}$ y la de los licitantes dentro de sus ofertas, En este sentido, además, cabe recordar que la fiabilidad de las estimaciones de tráfico ha sido, en algunos casos literalmente $^{10}$, uno los criterios de valoración de las ofertas contenidos en el pliego de cláusulas administrativas particulares de los concursos de concesión.

Desde un punto de vista técnico, González-Savignat, Matas y Raymond (2010) explican las tendencias a la sobreestimación inherentes a algunas modali-

\footnotetext{
${ }^{9}$ Art. 128 del Texto Refundido de la Ley de Contratos del Sector Público.

${ }^{10}$ Véase, por ejemplo, el subcriterio II.ii de la cláusula 10 del pliego de cláusulas administrativas particulares para el concurso concesión de la M12 (ORDEN FOM/541/2002, de 5 de marzo).
} 
dades estadísticas de predicción del uso de determinadas infraestructuras de transporte, especialmente durante los primeros años de disponibilidad de estas, así como los efectos sobre la evaluación del retorno de las inversiones subyacentes. Específicamente para el ámbito español, los autores señalan como una de las principales deficiencias de las bases de datos existentes sobre transporte y movilidad la falta de una fuente estadística sistematizada y suficientemente detallada (matrices origen-destino de los viajes, con datos de flujos agregados de tráfico y datos individuales, para cualquier modo de transporte, etc,) que permita aislar, convenientemente, las dificultades metodológicas de las estimaciones en modelos de demanda de este tipo y que, por tanto, puedan ser útiles en la predicción de uso y en la evaluación de inversiones.

No obstante, para enmarcar adecuadamente la constante presencia de sobreestimaciones en la historia del modelo concesional español, hay que tener en cuenta las investigaciones de BAIN (2009), que detectan una propensión similar en diversas experiencias internacionales. Así, un estudio pionero de la Banca JP Morgan (1997) sobre 14 autopistas de peaje de EUA reveló una sobreestimación de las previsiones de los proyectos respecto a las cifras reales de tráfico inicial del orden de un 25-30\%; un porcentaje similar de sobreestimación de las previsiones se detectó en los diversos estudios realizados por el propio Bain para la agencia Standard \& Poor's en los años 2002-2005, sobre una muestra inicial de 32 autopistas americanas que se amplió a 100 de ámbito internacional.

Bain explica la propensión a la sobeestimación de las previsiones iniciales en las concesiones de autopistas de peaje a partir de dos argumentos. Por un lado hay que tener en cuente que, para la captación de financiación en los mercados para un proyecto de este tipo, presentar unas mejores cifras de usuarios (y por tanto de ingresos) en los ejercicios iniciales de operación, permite amortiguar los riesgos financieros potenciales, en un momento especialmente sensible (cuando los flujos de efectivo serán menores y, en cambio, la financiación habrá sido desembolsada prácticamente en su totalidad), lo cual condicionará la curva de rendimiento de los activos. Por otro lado, resulta difícil desvincular la propensión a la sobreestimación de las previsiones iniciales de la tendencia, sistemáticamente observada, de que las concesiones de autopistas de peaje con financiación privada son comúnmente otorgadas a las ofertas de licitación que presentan las proyecciones de tráfico inicial más elevadas. Ciertamente, para el poder público otorgante, unas mejores previsiones de uso suponen, también, una mayor solidez financiera del proyecto e implican, además, unas tarifas unitarias iniciales más bajas para el usuario, lo que permite, en teoría, maximizar la función de utilidad social del proyecto.

En relación específicamente al caso de las concesiones problemáticas consideradas aquí, BAEZA Y VASALLO (2011: p. 59) profundizan en los argumentos de Bain, 
sugiriendo que la práctica de sobreestimar los volúmenes de tráfico puede ser un recurso de los licitadores para conseguir las adjudicaciones: "los licitadores acudieron a los concursos de las nuevas concesiones con ofertas muy agresivas. Los promotores de los proyectos de las nuevas autopistas confiaban en que, transcurridos unos años, podrían renegociar los términos de sus contratos con la Administración, puesto que ésta ya lo había hecho con anterioridad en numerosas ocasiones". Este esquema, sin embargo, sufrió unas inesperadas y fundamentales alteraciones con la llegada de la crisis económica y financiera a partir de 2008.

\section{EL PROBLEMA CREADO AL ESTADO POR LAS CONGE- SIONES DEFICITARIAS Y SUS INTENTOS DE SOLUGIÓN}

Ante la proliferación y diversidad de problemáticas que afectaron desde el principio a las nuevas concesiones, la Administración estatal planteó, en primera instancia, medidas de corrección individual para reestablecer el equilibrio económico. Sin embargo, las renegociaciones individuales acordadas resultaron poco efectivas para establecer unas condiciones de rentabilidad razonable a las concesiones, en parte porque no se trataban algunos de los problemas esenciales que tenían planteadas las adjudicaciones (es decir, las expropiaciones y la infrautilización de las vías). Por esta razón, las empresas concesionarias y sus partícipes continuaron ejerciendo tanto una decidida actuación litigante contra la Administración como una intensa acción de lobby y, finalmente, a partir de 2009 consiguieron incorporar, en normas estatales con rango de ley, medidas específicamente dirigidas a mejorar la viabilidad de las explotaciones y comprometer los recursos presupuestarios correspondientes. En concreto, se establecieron ${ }^{11}$ tres tipos de medidas dirigidas al reequilibrio económico y garantía de ingresos de las concesiones de algunas autopistas de peaje, entre ellas las que configuran nuestro grupo de análisis.

En primer lugar, se implementaron los préstamos participativos por sobrecostes de expropiaciones ${ }^{12}$, mediante los cuales la Administración asumiría la financiación del exceso abonado por expropiaciones respecto al $175 \%$ de las cantida-

${ }^{11}$ Las medidas se contienen en las disposiciones adicionales cuadragésima primera y cuadragésima segunda de la Ley 26/2009, de 23 de diciembre, de Presupuestos Generales del Estado para el año 2010 y en la disposición adicional octava de la Ley 43/2010, de 30 de diciembre, del servicio postal universal, de los derechos de los usuarios y del mercado postal.

${ }^{12}$ Las concesiones que se establecieron como potenciales beneficiarias de la medida fueron las siguientes: AP-7 Alicante-Cartagena y Cartagena-Vera, R-3 Madrid-Arganda, R-5 Madrid-Navalcarnero, R-4 Madrid-Ocaña, R-2 Madrid-Guadalajara, AP-51 Conexión de la AP-6 con Ávila y AP-61 Conexión de la AP-6 con Segovia, AP-6 Villalba-Adanero, M-12 Eje aeropuerto, AP-41 Madrid-Toledo, AP-7 Circunvalación de Alicante, AP-53 Santiago de Compostela-Alto de Santo Domingo. 
des previstas por la concesionaria en su oferta por este concepto (es decir, la concesionaria asumía el 75\% del sobrecoste), siempre que el importe de las expropiaciones haya sido determinado, en más del $50 \%$, mediante acuerdos de las instancias judiciales. Dichos préstamos, concedidos por el plazo restante de la concesión (con un límite de 50 años) se incorporaban como deuda subordinada en el pasivo a largo plazo del balance social, con tres años de carencia (incluidos los intereses). Su remuneración anual se establece como participación en una parte de los ingresos netos del peaje (el 75\% menos la amortización lineal de la inversión) proporcional al capital que, en cada momento, signifique el importe del préstamo en el conjunto de la inversión total, con un mínimo garantizado del 1,75\%. Para su devolución, la Administración estatal podrá acordar modificaciones de las concesiones que incrementen las tarifas o amplíen el plazo de concesión, "a los solos efectos de generar ingresos adicionales directa y exclusivamente destinados a amortizar el principal y los intereses" de los préstamos participativos. Hasta finales de 2011, los datos de la Delegación del Gobierno en las Sociedades Concesionarias de Autopistas Nacionales de Peaje muestran que sólo una parte de las concesiones potencialmente beneficiarias utilizó este mecanismo y por un importe agregado de unos 502,9 millones de euros.

En segundo lugar, se habilitó la posibilidad de compensar las obras adicionales ya ejecutadas "no previstas en los proyectos iniciales, y que se encuentren integradas en el dominio público estatal por ser de interés para la Administración concedente." La forma de compensación consistirá, preferentemente, en un incremento de tarifas i/o del plazo concesional y será determinada, en cada caso, por la Administración, previo acuerdo convencional con las concesionarias. En cualquier caso, tanto esta posibilidad como la de los préstamos participativos, implicará "la renuncia a entablar acciones contra el Estado, o el compromiso de desistir de las ya iniciadas, por razón del reequilibrio económico de la concesión, basadas tanto en el sobrecoste de las expropiaciones como en la ejecución de obras adicionales".

En tercer lugar, se creó el mecanismo de la cuenta de compensación, destinado a garantizar a determinadas concesionarias ${ }^{13}$, durante tres años, los ingresos equivalentes al $80 \%$ del tráfico previsto en el plan económico financiero presentado en la oferta de licitación. El saldo total de las aportaciones públicas necesa-

${ }^{13}$ Las concesiones que podían ser beneficiarias de la medida eran: AP-7 Cartagena-Vera, R-3 Madrid-Arganda, R-5 Madrid-Navalcarnero, R-4 Madrid-Ocaña, R-2 Madrid-Guadalajara, M-12 Eje aeropuerto, AP-41 Madrid-Toledo, AP-7 Circunvalación de Alicante, AP-36 Ocaña-La Roda y AP-7 Alto de las Pedrizas-Málaga. 
rias para ello ${ }^{14}$, a partir del tercer año, adquirirá la condición de un préstamo que será retribuido en condiciones similares a los concedidos por sobrecostes de expropiaciones, capitalizándose anualmente la retribución junto al saldo vivo. La cuenta se cancelará en el momento que las aportaciones privadas igualen al saldo de la misma. Las aportaciones públicas anuales, para cada concesión, no podrán superar el $49 \%$ del importe resultante de sumar a los ingresos anuales de peaje de la concesión la cantidad a consignar y, en conjunto, no podrán superar la consignación presupuestaria específicamente establecida. La tabla 4, en la columna destacada, ofrece una aproximación al impacto de la puesta en marcha del mecanismo de la cuenta de compensación sobre la cuenta de resultados total de las concesionarias; en el primer ejercicio de funcionamiento (2011), los ingresos por este concepto se acercaron al 90\% de los ingresos por peaje del total de concesiones analizadas.

TABLA 5. Ingresos por operaciones y resultados anuales en las concesiones problemáticas $(2010$ y 2011$)$. Millones de euros

\begin{tabular}{|c|c|c|c|c|c|c|c|}
\hline \multirow[b]{2}{*}{$\begin{array}{l}\text { Sociedad } \\
\text { concesionaria }\end{array}$} & \multirow[b]{2}{*}{ Concesión } & \multicolumn{2}{|c|}{ Ingresos de peajes } & \multicolumn{2}{|c|}{$\begin{array}{l}\text { Otros ingresos, } \\
\text { imputación de } \\
\text { subvenciones y cuen- } \\
\text { ta de compensación }\end{array}$} & \multicolumn{2}{|c|}{$\begin{array}{c}\text { Resultado de } \\
\text { operaciones } \\
\text { continuadas antes } \\
\text { de impuestos }\end{array}$} \\
\hline & & 2010 & 2011 & 2010 & 2011 & 2010 & 2011 \\
\hline Henarsa & $\begin{array}{l}\text { R-2 Madrid- } \\
\text { Guadalajara }\end{array}$ & 22.592 & 19.182 & 939 & 17.234 & -9.089 & 1.051 \\
\hline $\begin{array}{l}\text { Accesos de } \\
\text { Madrid } \\
(\mathrm{AM})\end{array}$ & $\begin{array}{l}\text { R-3 Madrid- } \\
\text { Arganda } \\
\text { R-5 Madrid- } \\
\text { Navalcarnero }\end{array}$ & 21.596 & 21.630 & 3.888 & 22.253 & -15.507 & -1.993 \\
\hline $\begin{array}{l}\text { Autopista } \\
\text { Madrid Sur }\end{array}$ & $\begin{array}{l}\text { R-4 Madrid- } \\
\text { Ocaña }\end{array}$ & 176.340 & 14.942 & 2.694 & 16.546 & 2.340 & 17.474 \\
\hline $\begin{array}{l}\text { Eje } \\
\text { Aeropuerto }\end{array}$ & $\begin{array}{l}\text { M12 Eje } \\
\text { aeropuerto }\end{array}$ & 4.713 & 4.377 & 189 & 4.960 & -2.393 & 1.725 \\
\hline $\begin{array}{l}\text { Autopista } \\
\text { Madrid-Toledo }\end{array}$ & $\begin{array}{l}\text { AP41 Madrid- } \\
\text { Toledo }\end{array}$ & 3.308 & 2.670 & 1.601 & 4.378 & -8.042 & -2.992 \\
\hline Aucosta & $\begin{array}{l}\text { AP-7 Cartagena- } \\
\text { Vera }\end{array}$ & 8.227 & 7.791 & 1.000 & 9.309 & -114.503 & -171.198 \\
\hline Ciralsa & $\begin{array}{l}\text { AP-7 Circunvala- } \\
\text { ción de Alicante }\end{array}$ & 6.397 & 5.768 & 2.878 & 7.903 & -12.517 & -6.683 \\
\hline
\end{tabular}

Fuente: Delegación del Gobierno en las Sociedades Concesionarias de Autopistas Nacionales de Peaje.

${ }^{14}$ Se establece que si, en alguno de los tres ejercicios de funcionamiento de la garantía, la concesionaria tiene unos ingresos reales de peaje superiores a los previstos en el plan económico financiero de la oferta de licitación, la sociedad abonará en la cuenta el 50\% del exceso de ingresos. 
La tipología de instrumentos concretos, en esencia garantías financieras y garantías de ingresos, se inscribe en los habitualmente presentes en otros países del entorno europeo. Estas soluciones han mantenido una gran prudencia formal en lo que respecta a la preservación de la naturaleza privada del riesgo de las concesiones, evitando así un desplazamiento del valor de las inversiones subyacentes hacia el balance público, lo cual hubiese agravado los ya acuciantes problemas de deuda pública. No obstante, como ponen de manifiesto los hechos relatados al principio de este artículo, la efectividad de estos instrumentos ha sido limitada, tanto en el sentido de asegurar la viabilidad económica de las concesiones, como en el de tranquilizar al sector de las empresas concesionarias y a las entidades financiadoras de los proyectos.

Descartada la posibilidad de encontrar, a medio plazo, unos gestores privados alternativos de las concesiones, no queda otra alternativa que la intervención pública para redefinir completamente el esquema de gestión de estas explotaciones, integrando en el perímetro público unos activos privados de un valor considerable, con un apalancamiento significativo y con una legislación que otorga fuertes garantías a los actuales adjudicatarios ante la Administración. En resumen, pues, el complicado reto que tiene la Administración del Estado es encontrar una solución que, simultáneamente, satisfaga entre otros los siguientes criterios:

1) minimizar el impacto del "rescate" de las concesiones en las maltrechas cuentas públicas,

2) proporcionar seguridad a los acreedores financieros de las empresas concesionarias en riesgo para preservar la confianza futura de los inversores en este tipo de proyectos en España,

3) evitar un grave quebranto a las empresas que configuran el capital de las concesionarias, entre ellas algunas de las mayores constructoras y operadoras de concesiones del país (véase la Tabla 2) y

4) garantizar la continuidad de la prestación del servicio público que ofrecen las infraestructuras subyacentes a las concesiones.

Sin embargo, una vez que el Gobierno del Estado haya conseguido armar, con los anteriores elementos una solución concreta para este episodio crítico, subsistirá la problemática de fondo que afecta al régimen concesional. Y no se trata tan sólo, ni en lo fundamental, de un problema de riesgo moral, sino que, en nuestra opinión, se trata de desarrollar les condiciones que permitan un mayor grado de transparencia y eficiencia, desde un punto de vista público, en la adjudicación y operativa de las diversas fórmulas contractuales de colaboración pú- 
blico-privada. Un desarrollo como el propuesto pasa, esencialmente, por una operación que puede parecer contradictoria: incrementar el rigor en la asignación del riesgo empresarial que deben asumir las empresas adjudicatarias y, a la vez, flexibilizar la garantía del equilibrio económico. Todo ello en un marco de mayor transparencia de los procesos de renegociación.

\section{DEFICIENCIAS EN LA TRANSPOSICIÓN ESPAÑOLA DE ALGUNOS PRINGIPIOS VERTEBRADORES DE LA CO- LABORACIÓN PÚBLICO-PRIVADA}

\section{El concepto de riesgo y ventura}

Aunque la figura del contrato de concesión tiene una larga trayectoria en el derecho administrativo español, su contenido actual, alineado con el criterio europeo, se empezó a configurar en $2003{ }^{15}$. La definición vigente (art. 7.1. del Texto Refundido de la Ley de Contratos del Sector Público ${ }^{16}$ ) del contrato de concesión de obra pública lo tipifica como aquel que tiene por objeto no sólo la realización por parte del concesionario de algún tipo de obra que responda a necesidades concretas del sector público, sino también “(...) la conservación y mantenimiento de los elementos construidos, y en el que la contraprestación a favor de aquél consiste, o bien únicamente en el derecho a explotar la obra, o bien en dicho derecho acompañado del de percibir un precio". La concesión en el derecho español actual es, pués, parte de un amplio conjunto de figuras contractuales ${ }^{17}$ que tienen por objeto la provisión privada de infraestructuras de interés público, concepto que se acostumbra a designar genéricamente como colaboración público-privada $(\mathrm{CPP})^{18}$.

Diversos factores han contribuido a la difusión internacional de la CPP. Entre ellos, se acostumbra a citar las mejoras en eficiencia que aporta la combinación de provisión y operación de una infraestructura de interés público a cargo

${ }^{15}$ La derogada Ley 13/2003, de 23 de mayo, reguladora del contrato de concesión de obras públicas (LRCCOP) definió, en su apartado cinco, que añadía un nuevo artículo 220.1 al TRLCAP de 2000, el contrato de concesión de obra pública en términos bastante similares a los actualmente vigentes.

${ }^{16}$ Real Decreto Legislativo 3/2011, de 14 de noviembre, por el que se aprueba el texto refundido de la Ley de Contratos del Sector Público (TRLCSP).

${ }^{17}$ Para una relación bastante completa de las fórmulas posibles en el derecho español, véase PUERTO CELa (2006: p. 100).

18 Con esta expresión nos referimos a las diversas fórmulas de Public-Private Partnership. Aunque la traducción aquí utilizada ha sido discutida por algunos autores que prefieren traducirla como "Asociación Público-Privada", hemos preferido seguir la traducción castellana empleada por la UE. 
de un operador privado, en determinados casos, respecto a la contratación tradicional (lo que se conoce como value for money). Pero ha sido, sobretodo, el especial tratamiento que tienen los importes dedicados a la financiación de estas infraestructuras en la contabilidad nacional, si concurren determinados requisitos, lo que ha contribuido a su extensa implantación. Al tratarse de fórmulas en las que el sector privado asume la construcción, financiación y operación de la infraestructura de interés público, las instituciones internacionales que emiten las normas contables han asumido el criterio de que el valor del activo subyacente no se integra en las cuentas públicas y, en contrapartida, tampoco la financiación necesaria para la construcción computa como gasto público, es decir, la operación no tiene efectos sobre el déficit ni sobre la deuda pública.

EuRostat (2010) establece, para que esta consideración tenga efecto, que la vinculación contractual de la CPP debe asignar al concesionario la totalidad del riesgo de construcción ${ }^{19}$ del activo subyacente y, simultáneamente, o bien el riesgo de disponibilidad ${ }^{20}$ o bien el de demanda ${ }^{21}$ (§ VI.5.6); específicamente, para las concesiones, precisa que debe acreditarse que los pagos del gobierno "(...) no constituyen la mayoría de los ingresos de la corporación [concesionaria] en virtud de los contratos, ya sea directa o indirectamente, y el gobierno no proporciona ningún otro tipo de apoyo en forma de garantías o de financiación directa” (§ VI.4.19). En síntesis, lo que exige la normativa estadística europea para no integrar la inversión canalizada a través de CPPs a efectos del cálculo del déficit público, es que la fórmula contractual establezca una transferencia, de forma clara y mayoritaria, de los riesgos inherentes a la provisión y operación de la infraestructura subyacente al operador privado.

Aunque el "riesgo y ventura", en la legislación española, constituye el principio general de la ejecución del contrato administrativo (art. 215 TRLCSP), parece claro que el sentido que adquiere dicho principio en las concesiones no puede limitarse al alcance que se da a este concepto, por ejemplo, en un contrato pú-

19 Bajo este concepto se incluyen las consecuencias económicas de determinados acontecimientos o circunstancias que tienen como resultado retrasos en la entrega o puesta en servicio de la infraestructura, la aparición de deficiencias diversas en ellas, las desviaciones significativas de los costes respecto a los inicialmente previstos, así como otras razones externas que dificulten la ejecución del contrato, como las problemáticas medioambientales o judiciales.

${ }^{20}$ Cuando la retribución del privado depende, de forma automática y significativa, de que los activos subyacentes estén en condiciones de prestar los servicios acordados en les condiciones de volumen y calidad establecidos en el contrato.

${ }^{21}$ Cuando la retribución del privado se vincula mayoritariamente al uso efectivo de la infraestructura por parte de los usuarios finales. 
blico de obra. El derecho español, en su caracterización textual del contrato de concesión de obra pública a partir de la LRCGOP de 2003, asume con claridad el principio de transferencia de riesgos, tanto al delimitar los sistemas de retribución del concesionario (derecho a explotación y/o precio), como al establecer el principio de "riesgo y ventura" para la ejecución del contrato (art. 7.2 TRLCSP). El criterio jurídico europeo interpreta que, con carácter global, la asunción del riesgo por parte del adjudicatario debe ser "substancial" (CONSEJO EUROPEO, 2011), incluyendo la posibilidad de que el contratista no recupere, mediante las contraprestaciones estipuladas, las inversiones realizadas o no cubra los costes en que haya incurrido para construir y explotar los activos objeto de la concesión, en unas condiciones estándar de operación. Y éste es un punto central para la tesis que desarrollamos es este artículo.

El principio de "riesgo y ventura" en los contratos de concesión en España sólo admite la salvedad de los casos de fuerza mayor, que se identifican con los efectos catastróficos derivados de fenómenos naturales o los destrozos ocasionados por situaciones de violencia colectiva grave (art. 231.2 TRLCSP). Como recuerda BAEZA (2008), en la fase inicial de tramitación del texto del proyecto de LRCCOP de 2003, la salvedad aludía al concepto más genérico de "causas impredecibles", que finalmente fue substituido por el vigente de "fuerza mayor". IzQUIERDO Y VASSALLO (2002: p. 37), entre otros autores, defendieron con ocasión del debate del proyecto de LRCCOP la conveniencia de restituir las "circunstancias impredecibles", las cuales debían cumplir, simultáneamente, las condiciones de ausencia de cualquier posibilidad lógica de ser esperables por parte del adjudicatario y de ser inevitables para él. La introducción de este criterio no sólo proporcionaría, en opinión de sus defensores, un equilibrio más razonable de riesgos soportados por el concesionario, sino que además reduciría la litigiosidad entre poder adjudicador y adjudicatarios en estos contratos. Aunque el criterio de "fuerza mayor" fue, finalmente, el que prevaleció en la ley, hay que decir que la jurisprudencia incorporó, parcialmente, las "circunstancias imprevisibles" como un criterio a considerar en determinadas alteraciones del equilibrio económico. ARIMANY (2011), por ejemplo, considera que la sentencia del TS, de mayo de 2011, referida a la autopista Madrid-Toledo (AP-41), en la parte relativa a la anulación de la prolongación del trazado hasta Andalucía se fundamenta en la apreciación de la existencia un riesgo imprevisible cuyo impacto sobre la economía de la concesión debe corregirse, aunque recomienda prudencia en la interpretación de la jurisprudencia, dado que la misma sentencia opera en un sentido distinto al valorar el factum principis aplicado a la ampliación de la M-407, una alternativa sin coste para el usuario de la AP-41.

Como hemos visto, el TRLCSP establece dos modalidades básicas para la remuneración del concesionario: la "explotación de la obra" o la de complementar 
este derecho con la percepción de un "precio". En consonancia con la legislación europea, hay que interpretar que el derecho de explotación transfiere, también, los riesgos de explotación. Así, el marco que establece el derecho español para las concesiones transfiere al adjudicatario el riesgo de construcción (incluido en el concepto de "riesgo y ventura"), así como el de demanda y, potestativamente, también el de disponibilidad (como fórmulas de retribución del contrato). En la literatura reciente se ha producido una intensa reflexión sobre cual de estos dos últimos riesgos (demanda o disponibilidad) es más eficiente trasladar al ámbito privado en función de la tipología de infraestructura subyacente a la CPP. En parte, este proceso ha sido inducido por el incremento de la aversión al riesgo de demanda que han experimentado las entidades financiadoras de este tipo de proyectos, especialmente desde la crisis financiera de $2008^{22}$. Así, por ejemplo, el Ministerio de Fomento español avanzó, en 2010, la licitación de un considerable paquete de infraestructuras que debían ejecutarse mediante la concesión de obra pública y con una remuneración a los adjudicatarios mediante pagos por disponibilidad únicamente ${ }^{23}$. La coyuntura económica y sus efectos, sin embargo, no han hecho menos pertinentes las bases teóricas de estas reflexiones. SÁnchez SoLíÑo (2012), por ejemplo, admite que "no existe un planteamiento teórico que avale de forma general las soluciones habituales de transferir el riesgo de demanda, en su totalidad, al agente, o, por el contrario, excluir cualquier transferencia del riesgo de demanda, basando la relación contractual exclusivamente en la transferencia del riesgo de disponibilidad". No obstante, su modelo teórico de análisis estudia la maximización de la utilidad social total, bajo diferentes supuestos, a partir del objetivo de reducir el coste de la financiación (entendido como una reducción de la aversión al riesgo de un proyecto de infraestructuras por parte del mercado financiero) en condiciones de una elevada incertidumbre sobre los flujos de tráfico y una insuficiente evaluación del proyecto por parte de la Administración. En el ámbito de las autopistas de peaje en España, concluye, se ha dado una tendencia de la administración a transferir una proporción demasiado elevada del riesgo de demanda a los concesionarios y propone un despla-

${ }^{22}$ El debate, sin embargo, no nace con esta crisis. En el Reino Unido, por ejemplo, los proyectos de la segunda generación de la Private Finance Iniciative (la fórmula originaria de la CPP actual), iniciados a principios del siglo XXI, basaron su esquema de pago mayoritariamente en la disponibilidad.

23 Presentado en abril de 2010, el llamado Plan Extraordinario de Infraestructuras (PEI) pretendía avanzar, para el periodo 2010-2011, un ambicioso paquete de 17.000 M€ en proyectos de CPP planificados en el Plan Estratégico de Infraestructuras y Transporte (2005-2020). La evolución de la crisis económica impidió la plena ejecución del plan. 
zamiento hacia los riesgos de disponibilidad, introduciendo o ampliando la parte de retribución vinculado al cumplimiento de indicadores de calidad en el mantenimiento y operación de estas concesiones ${ }^{24}$.

El criterio de "riesgo y ventura" no es incompatible con el hecho de que la Administración prevea simultáneamente un abanico, más a o menos complejo y diverso, de fórmulas de garantía para los posibles inversores y adjudicatarios en contratos de CPP, conocidas habitualmente como garantías de Estado. Con esta denominación se designa a cualquier obligación secundaria que vincule legalmente el gobierno a asumir una obligación de pago en caso de que durante el desarrollo de un proyecto de CPP, promovido por cualquier administración de un país, concurra una circunstancia, especificada en la propia garantía, que ponga en peligro el adecuado desarrollo financiero del proyecto.

En principio, la finalidad última de estos instrumentos debe ser evitar que las incertidumbres que rodean los proyectos de CPP, dada su habitual complejidad y el dilatado periodo de su ejecución, dificulte o imposibilite la obtención de la financiación privada de los mismos. Este objetivo, de acuerdo con los criterios del derecho europeo, debe conseguirse sin que las garantías de Estado desplacen mayoritariamente los riesgos hacia el sector público (lo que alteraría la clasificación de estos proyectos a efectos de la contabilidad nacional) y respetando el market economy investor principle, esto es, que las garantías de Estado sean retribuidas por la empresa de CPP a la Administración al precio que cobraría un operador del mercado por el mismo servicio (en caso contrario, las garantías serían calificadas de ayudas de Estado a los efectos del derecho comunitario).

Para la casuística analizada aquí, resulta particularmente relevante tener presente que la legislación actual contempla como causa de resolución de una concesión, entre otras, "la declaración de concurso o la declaración de insolvencia en cualquier otro procedimiento" (letra b, art. 269 TRLCSP) ${ }^{25}$. Sin embargo, dentro de este supuesto, sólo se señala, imperativamente, como motivo de resolución la apertura de la fase de liquidación en el proceso concursal, mientras que "en los

\footnotetext{
${ }^{24}$ En un sentido contrario a la práctica licitadora habitual en las CPP, el trabajo de SÁNCHEz SOLIÑo (2012) recomienda que para determinadas infraestructuras y servicios sobre los cuales la Administración no pueda establecer un cuadro de indicadores de calidad y, sin embargo, éstos si puedan ser percibidos claramente por los usuarios (por ejemplo, en un hospital), el riesgo de disponibilidad sea desplazado por el de demanda en la retribución del adjudicatario

${ }^{25}$ En la LRCCOP, de 2003, el texto equivalente hace referencia a los procedimientos legales vigentes en aquel momento, en concreto, "la declaración de quiebra, de suspensión de pagos, de concurso de acreedores o de insolvente fallido en cualquier procedimiento o el acuerdo de quita y espera".
} 
restantes casos, será potestativo para la parte a la que no le sea imputable la causa instar la resolución. (art, 270.2 TRLCSP). Llegados a la efectiva resolución de la concesión, por obligación o por decisión de la Administración, "la Administración abonará al concesionario el importe de las inversiones realizadas por razón de la expropiación de terrenos, ejecución de obras de construcción y adquisición de bienes que sean necesarios para la explotación de la obra objeto de la concesión. Al efecto, se tendrá en cuenta su grado de amortización en función del tiempo que restara para el término de la concesión y lo establecido en el plan económico-financiero" (art. 271.1 TRLCSP); adicionalmente, en los supuestos de resolución únicamente por razones de conveniencia del sector público ${ }^{26}$, se estipula también que "la Administración concedente indemnizará al concesionario por los daños y perjuicios que se le irroguen. Para determinar la cuantía de la indemnización se tendrán en cuenta los beneficios futuros que el concesionario dejará de percibir, atendiendo a los resultados de explotación en el último quinquenio cuando resulte posible, y a la pérdida del valor de las obras e instalaciones que no hayan de ser entregadas a aquélla, considerando su grado de amortización" (art. 271.3 TRLCSP). Es de destacar que, en relación a la LRCCOP, ha desaparecido la previsión de que la indemnización al concesionario por las inversiones realizadas sólo se le abonará después de solventar las obligaciones que este hubiese contraído con terceros para financiar las obras.

\section{La preservación del equilibrio económico}

En palabras de ARIMANY (2011: p. 96), existe "una suerte de necesaria convivencia y de tensión, inmanente a las concesiones, entre, por una parte, el principio de riesgo y ventura y, por otra parte, el principio de remuneración suficiente", un concepto del vigente, aunque antiguo, Reglamento de Servicios de las Corporaciones Locales (1955) ${ }^{27}$. Aunque se han emitido algunas opiniones favorables a la incorporación a la normativa sobre concesiones de la referencia explícita al principio de remuneración suficiente, IZQUIERDO Y VASSALLO (2002: p.

26 En concreto se consideran los supuestos detallados en los párrafos g), h) e i) del artículo 269 TRLCSP, es decir, "g) El rescate de la explotación de la obra pública por el órgano de contratación. Se entenderá por rescate la declaración unilateral del órgano contratante, discrecionalmente adoptada, por la que dé por terminada la concesión, no obstante la buena gestión de su titular. h) La supresión de la explotación de la obra pública por razones de interés público. i) La imposibilidad de la explotación de la obra pública como consecuencia de acuerdos adoptados por la Administración concedente con posterioridad al contrato.".

27 “(...) en todo caso, la retribución prevista para el concesionario deberá ser calculada de modo que permita, mediante una buena y ordenada administración, amortizar durante el plazo de la concesión el costo de establecimiento del servicio y cubrir los gastos de explotación y un margen normal de beneficio industrial" (art. 129.3). 
38) señalan que la referencia directa al principio de "remuneración suficiente" obviaría que "las concesiones son en la mayoría de los casos monopolios naturales en los que se introduce la competencia en el proceso de licitación a fin de lograr que el consorcio adjudicatario sea el más eficiente y que, por tanto, el hecho de garantizar un beneficio estable al concesionario incentiva a que los licitadores, sabiendo que van a ser compensados en un futuro, no declaren en sus ofertas la información real sobre sus predicciones, lo que claramente va en contra de la eficiencia en el proceso."

El nuevo modelo concesional que parece plantearse en el derecho administrativo español, por lo menos desde 2003, fundamenta la actuación pública garantizando los legítimos intereses del socio privado en el concepto de "mantenimiento del equilibrio económico" 28 , más que en preservar, ante cualquier riesgo posible, el beneficio del concesionario y de los inversores en la infraestructura. Con ello se pretende, al menos en la intención expresada por el legislador, desplazar la idea generalizada, reconocida en el apartado segundo de la exposición de motivos de la LRCCOP, de la existencia en España de un compromiso absoluto de la Administración con el mantenimiento de la rentabilidad acordada con los concesionarios. Con este objetivo, el artículo 258.1 TRLCSP circunscribe la extensión del derecho del adjudicatario al mantenimiento del equilibrio económico de la concesión y la prerrogativa de la Administración a "(...) los términos que fueron considerados para su adjudicación, teniendo en cuenta el interés general y el interés del concesionario (...)". Los supuestos que establece para que la Administración venga obligada a restablecer el equilibrio económico del contrato son tres (art. 258.2 TRLCSP): la modificación, por parte de la Administración y por razones de interés público, de las condiciones de explotación de la obra (ius variandi); la ruptura sustancial de la economía de la concesión directamente determinada por causas de fuerza mayor o actuaciones de la Administración (factum principis) y, finalmente, en presencia de los supuestos que se establezcan en el propio contrato para su revisión.

Dado que las concesiones de obra pública son unos contratos a largo plazo y en los cuales existe una estrecha vinculación entre su objeto y la satisfacción de intereses públicos, es perfectamente razonable que la ley prevea un escenario flexible de la ejecución de los mismos, incluso esperando variaciones introducidas por la propia Administración en aras a una mayor salvaguarda de los intereses

${ }^{28}$ La legislación española no define con precisión el concepto de equilibrio económico de una concesión, aunque sí establece, para el concesionario, el derecho al mantenimiento del mismo en la letra b) del artículo 245 TRLCSP. 
públicos, sin que ello afecte a la rentabilidad pactada con el adjudicatario. Sin embargo, no cualquier circunstancia que impida al concesionario lograr la rentabilidad inicialmente estipulada (o comprendida entre los umbrales mínimo y máximo) le faculta para apelar a dicha flexibilidad. En aquellos supuestos no previstos por la ley debería prevalecer, pues, el principio de "riesgo y ventura" del concesionario.

El restablecimiento del equilibrio económico "se realizará mediante la adopción de las medidas que en cada caso procedan" (art. 258.3 TRLCSP), las cuales podrán consistir en las modificaciones de las tarifas, el plazo concesional o de cualquier cláusula de contenido económico incluida en el contrato. Restaurar el equilibrio económico es la única razón que la ley contempla como causa de prorroga de los plazos de duración fijados en los pliegos de condiciones de las concesiones (art. 268.2 TRLCSP) ${ }^{29}$. En los casos de factum principis o fuerza mayor se establece el límite, para las prórrogas del plazo concesional, del 15 por ciento de su duración inicial, en aquellas concesiones con un mínimo del $50 \%$ de sus ingresos vinculados a tarifas abonadas por el usuario.

La experiencia histórica de las concesiones de autopistas de peaje en España muestra una propensión muy notable a las renegociaciones, fundamentadas en causas muy dispares o simplemente desconocidas. BAEZA (2008: pp. 143-144) señala que, antes de 2005, el 55\% de las concesiones de autopistas estatales de peaje habían tenido una o más renegociaciones, un 75\% de las cuales se produjeron antes de los 10 años de concesión; BAEZA Y VASSALlo (2011: p. 56) calculan una media de ocho años entre la adjudicación y la primera renegociación para estas concesiones. Algunas veces, los nuevos términos de la concesión son aprobados en forma de norma y publicados en el boletín oficial, pero esto no sucede siempre. De las 121 renegociaciones efectivas producidas, antes de 2005, en las concesiones de la REAP, sólo 55 tuvieron publicación oficial (BAEZA, 2008: p. 145).

${ }^{29}$ La redacción del artículo correspondiente en la Ley de 2003 establecía un abanico más amplio de causas:

"Artículo 263. Plazo de las concesiones.

4. Los plazos fijados en los pliegos de condiciones podrán ser prorrogados potestativamente, más allá de los límites establecidos, hasta los 60 y 25 años, respectivamente, para restablecer el equilibrio económico del contrato o, excepcionalmente, para satisfacer los derechos de los acreedores en el caso en que los derechos de crédito del concesionario hayan sido objeto de titulización."

En la Ley de 2007 también se contemplaban, explícitamente, las prórrogas por suspensiones en la ejecución de obras por causas no imputables al concesionario (ahora en el art. 242.2 TRLCSP),que implícitamente también se incorporan en el nuevo texto, aunque en sentido estricto no supone una ampliación del plazo de explotación de la obra, sino un diferimiento de su puesta en servicio. 
GUASCH (2005) definió la renegociación como cualquier enmienda significativa del contrato concesional y, por tanto, con una repercusión directa sobre la planificación económico-financiera del mismo. El Plan Económico-Financiero (PEF) de una concesión es el documento, integrado en la oferta presentada por cada licitante, que estipula, entre otros aspectos, “(...) el sistema de tarifas, la inversión y los costes de explotación y obligaciones de pago y gastos financieros, directos o indirectos, estimados. Deberá ser objeto de consideración específica la incidencia en las tarifas, así como en las previsiones de amortización, en el plazo concesional y en otras variables de la concesión previstas en el pliego, en su caso, de los rendimientos de la demanda de utilización de la obra (...)" (apartado $4^{\circ}$ del artículo 131.1.c TRLCSP). El término fue introducido por el Decreto 215/1973, de 25 de enero, sobre el Pliego de Cláusulas Generales para la construcción, conservación y explotación de las autopistas en régimen de concesión, todavía vigente. La cláusula 46 de este Pliego establece que "el PEF, presentado al concurso formando parte de la proposición y aprobado por el Decreto de adjudicación de la concesión, constituirá la base económico-financiera de ésta". El sentido general de la normativa apunta a que, una vez perfeccionado el contrato, el PEF deviene un documento vinculante para ambas partes. De hecho, toda modificación del proyecto, "deberá recoger en todo caso, mediante los oportunos ajustes, los efectos derivados del incremento o disminución de los costes" en el PEF (art. 243 TRLCSP). A partir de 2003, con la LRCCOP, el PEF debe entenderse referido a los dos niveles de rendimiento de la concesión (el mínimo y el máximo) contemplado en las ofertas.

La renegociación es un proceso inherente a los contratos incompletos. De forma esquemática, en la teoría económica, un contrato incompleto es aquel que no prevé, al inicio de la vinculación, todos los eventos que pueden acontecer a lo largo de su duración y que tienen un efecto directo sobre su desarrollo. Las concesiones de obra pública son, por la amplitud de factores que inciden en su ejecución y su prolongada duración, un ejemplo natural de contrato incompleto. Como muestran Guasch (2005) y Engel, Fischer, Galetovic y Hermosilla (2009) la experiencia concesional internacional constata una reiterada utilización de las renegociaciones. Sin embargo, a pesar de la naturalidad del hecho en sí, también se detectan la existencia de renegociaciones provocadas, con una estrategia oportunista, por el adjudicatario, en un contexto institucional que favorece netamente su posición, lo cual aboca a una negociación con un elevado grado de asimetría entre las partes (ATHIAS y SOUBEYRAn, 2012).

El nuevo criterio del derecho comunitario parece configurarse entorno a la idea de que la legislación de los países miembros debería incorporar, por lo menos en determinadas renegociaciones, nuevos procesos de concurrencia pública. Las autoridades europeas están considerando una propuesta de directiva que tie- 
ne como objetivo directo establecer como criterio común que "toda modificación sustancial de las disposiciones de una concesión durante su periodo de vigencia será considerada una nueva adjudicación a efectos de lo dispuesto en la presente Directiva y conllevará un nuevo procedimiento de ejecución regido por la misma" (CONSEJO EuROPEO, 2011: art.42.1) y detalla el concepto de modificación substancial, con carácter general, como aquella que cumpla alguna de las siguientes condiciones: "(a) que la modificación imponga condiciones que, si hubiera figurado en el procedimiento original de adjudicación de la concesión, hubieran dado lugar a una selección distinta de solicitudes de participación, o hubieran dado lugar a la adjudicación de la concesión a otro candidato o licitador; (b) que la modificación cambie el balance económico de la concesión a favor del concesionario; (c) que la modificación amplíe considerablemente el ámbito de la concesión, cubriendo suministros, servicios u obras no previstos originalmente" (art. 42.2).

\section{ALGUNAS IDEAS PARA UN FUTURO VIABLE DEL SIS- TEMA CONGESIONAL Y LA COLABORACIÓN PÚBLI- CO-PRIVADA EN ESPAÑA}

\section{Una propuesta de solución concreta a las autopistas de peaje adjudicadas a partir de 1998}

Aunque los medios de comunicación se han hecho eco, periódicamente, de las dificultades que atraviesan algunas de las concesionarias y, también, de las posibles soluciones que estaría valorando la Administración de Estado, esta no ha adoptado, en el momento de redactar este artículo, una decisión definitiva. Por lo que respecta al método de solución, todo parece apuntar a que la Administración estaría valorando una solución que implique el traspaso e integración de las concesiones en algún ente estatal de carácter mixto (posiblemente con la participación de acreedores financieros y algunas de las sociedades concesionarias o sus partícipes), el posterior saneamiento de las mismas, eventualmente con la inyección de recursos públicos, para su devolución final al sector privado mediante la fórmula jurídica oportuna. La creación de una sociedad mercantil específica para este propósito es una posibilidad perfectamente viable ${ }^{30}$, pero en nuestra opinión el Estado cuenta con alguna alternativa mejor.

\footnotetext{
${ }^{30}$ De hecho ya hubo una proceso similar en la experiencia de la extinta Empresa Nacional de Autopistas (1984-2003), ente estatal que agrupó diversas concesiones de autopistas de peaje hasta su privatización.
} 
En buena medida, la solución que se arbitre para corregir la situación económica y financiera de la concesión de las autopistas de peaje problemáticas, guarda considerables similitudes con el proceso de saneamiento aplicado a determinados activos inmobiliarios en manos de las entidades financieras y que deterioraban las posibilidades de recapitalización de éstas. La transferencia de estos activos a una sociedad mixta, la Sociedad de Gestión de Activos Procedentes de la Reestructuración Bancaria (SAREB) ${ }^{31}$, mediante una compensación económica a la entidad propietaria, y la posterior venta de estos activos en una operación de mercado, tiene un cierto paralelismo con el procedimiento que hemos referido antes respecto a las autopistas consideradas. En la mayoría de las sociedades concesionarias examinadas existe una notable participación de las cajas de ahorro en su capital social (hasta el 18\% de los $716 \mathrm{M} €$ de capital social agregado, entre participaciones directas e indirectas), con una participación destacada del Grupo CajaMadrid (76M€), además de otro $17 \%$ propiedad de sociedades completamente en manos del grupo Abertis (con una participación substancial de otra entidad de esta naturaleza).

Todo ello nos hace expresar que, en nuestra opinión, la mejor solución que podría disponer el Estado para solucionar el caso de las concesiones de autopista de peaje problemáticas sería el traspaso de las mismas a la SAREB. Este solución nos parece la de tramitación legal más sencilla, con la suficiente flexibilidad para la gestión de los activos y la que minimizaría el impacto sobre las cuentas públicas de los flujos económicos que se aflorarían con la operación.

Como se sabe, la SAREB se creó como una sociedad anónima de gestión de activos recibidos en aplicación de la potestad que se otorga al FROB de "obligar a una entidad de crédito a transmitir a una sociedad de gestión de activos determinadas categorías de activos que figuren en el balance de la entidad o a adoptar las medidas necesarias para la transmisión de activos que figuren en el balance de cualquier entidad sobre la que la entidad de crédito ejerza control en el sentido del artículo 42 del Código de Comercio, cuando se trate de activos especialmente dañados o cuya permanencia en dichos balances se considere perjudicial para su viabilidad, a fin de dar de baja de los balances dichos activos y permitir la gestión independiente de su realización" (Art. 35.1 Ley 9/2012). De acuerdo con la norma de creación de la SAREB, entre las diferentes categorias de activos

${ }^{31}$ La regulación de esta sociedad se encuentra en el Capítulo VI y determinadas disposiciones adicionales de la Ley 9/2012, de 14 de noviembre, de reestructuración y resolución de entidades de crédito, procedente de la tramitación parlamentaria del Real Decreto-ley 24/2012, de 31 de agosto y desarrollada por el Real Decreto 1559/2012, de 15 de noviembre, por el que se establece el régimen jurídico de las sociedades de gestión de activos. 
tansmisibles se contemplan los "derechos de crédito, instrumentos representativos del capital social de otras entidades o activos inmateriales" (apartado $1^{\circ}$ de la letra a), artículo 5.1 RD 1559/2012). En cualquier caso, los activos a transferir son determinados por el FROB, que también conserva la potestad de modificar, sucesivamente, la relación de activos transferibles (art. 6.2 RD 1559/2012). La regulación de la SAREB permite una gestión diferenciada de estos activos, al habilitar la constitución de un patrimonio separado carente de personalidad jurídica, de los contemplados en el artículo 29 del RD 1159/2012 (en desarrollo de la disposición adicional décima Ley 9/2012),

Vehicular a través de la SAREB la operación de recuperación de las autopistas mencionadas presenta una ventaja muy significativa en términos presupuestarios. De acuerdo con la decisión de Eurostat explicitada en la carta del director de esta agencia a las autoridades españolas de 26.03.2013 32 , los recursos públicos aportados a la SAREB no computarán a efectos de deuda pública en la contabilidad nacional al aceptarse la clasificación de este ente como parte del sector de las corporaciones financieras, es decir, en el sector privado, sin integración con los balances públicos. La creación ex profeso de una sociedad mercantil, por el contrario, debería solicitar específicamente a Eurostat su exclusión a efectos de déficit público, un aspecto que puede parecer trivial, pero que no lo es en absoluto ${ }^{33}$. Aunque en el diseño societario es previsible que se opte por una arquitectura de CPP, no es sencillo que Eursotat acepte como tal lo que, proviniendo de una fórmula de este tipo, no deja de ser una operación que revierte en el sector público gran parte de los riegos y garantías del proyecto asumidos anteriormente por el sector privado.

En cierta medida, nuestra propuesta de solución presenta notables similitudes con situaciones precedentes. En particular, nos referimos a toda la situación vivida por la concesionaria ACESA, a principios de los años 80 del siglo XX. La propiedad de dicha concesionaria fue transferida al Fondo de Garantía de Depósitos (FGD) durante el intento de rescate de la entidad financiera que era su accionista mayoritario, el desaparecido Bankunión, donde permaneció hasta su privatización en 1987.

La otra gran cuestión que plantea la resolución del problema de las autopistas de peaje que hemos analizado es, evidentemente, el coste que supondrá para

\footnotetext{
${ }^{32}$ El texto íntegro de la carta está disponible en

http://epp.eurostat.ec.europa.eu/portal/page/portal/government_finance_statistics/documents/E S-Classification_of_SAREB.pdf.

${ }^{33}$ En este sentido, habría que recordar la experiencia de Madrid Calle 30.
} 
el Estado. Sobre este particular, tanto en la prensa como en algunos estudios han aparecido cifras en un intervalo notablemente disperso, que va desde los 3.000 a los 8.000 millones de euros ${ }^{34}$, entendiendo que nos estamos refiriendo exclusivamente al coste de traspasar los activos desde las actuales concesionarias al perímetro público (indemnización de los adjudicatarios y refinanciación de la deuda), y no los costes adicionales que supondrá la posterior operativa de las concesiones. Conviene tener en cuenta, además, que en este caso cualquier valoración pericial del coste de la operación tiene un valor de punto de partida, dado que, al final, debe ser sometido a negociación y acuerdo entre las partes implicadas.

En este contexto, parece que los más sensato sería partir de la aplicación del art. 271.1 TRLCSP, que insta a la Administración a compensar al privado la parte no amortizada de la inversión en activos. En la Tabla 6 se recogen estos valores, a 31.12.2011, en términos de valoración contable, los cuales deberían matizarse, por lo menos, con los siguientes importes:

a) La existencia de imputaciones en concepto de deterioro del inmovilizado con cargo a las cuentas de resultados anuales en cada una de las sociedades concesionarias.

b) Las provisiones, en concepto de minusvaloración de la inversión, practicadas por cada partícipe del capital social de las concesionarias en sus respectivos balances.

c) La transposición de los criterios generales de valoración de la SAREB (capítulo III RD 1559/2012) a la naturaleza concreta de los activos involucrados en esta operación, en el caso de que esta sociedad fuera el instrumento vehicular definitivamente elegido.

\footnotetext{
${ }^{34}$ BeL (2010: p. 222), por ejemplo, apuntó una cifra entre 4.000 y 5.000 millones de euros sólo de deuda.
} 
TABLA 5. Inversión en autopista y amortización de autopista en las concesiones problemáticas (a 31.12.2011). Miles de euros

\begin{tabular}{|c|c|c|c|c|}
\hline Concesión & Concesionaria & $\begin{array}{l}\text { Amortización } \\
\text { de autopista } \\
\text { acumulada }\end{array}$ & $\begin{array}{l}\text { Inversión en } \\
\text { autopista }\end{array}$ & $\begin{array}{l}\text { Activo neto en } \\
\text { autopistas }\end{array}$ \\
\hline $\begin{array}{l}\text { R-2 Madrid - } \\
\text { Guadalajara }\end{array}$ & Henarsa & 107.274 & 774.932 & 667.658 \\
\hline $\begin{array}{l}\text { R-3 Madrid - } \\
\text { Arganda }\end{array}$ & $\begin{array}{l}\text { Accesos de } \\
\text { Madrid (AM) }\end{array}$ & 103.889 & 1.247 .468 & 1.143 .579 \\
\hline \multicolumn{5}{|l|}{$\begin{array}{l}\text { R-5 Madrid - } \\
\text { Navalcarnero }\end{array}$} \\
\hline R-4 Madrid - Ocaña & $\begin{array}{l}\text { Autopista Madrid } \\
\text { Sur }\end{array}$ & 36.303 & 1.217 .265 & 1.180 .962 \\
\hline M12 Eje aeropuerto & Eje Aeropuerto & 21.818 & 406.312 & 384.494 \\
\hline $\begin{array}{l}\text { AP41 Madrid - } \\
\text { Toledo }\end{array}$ & $\begin{array}{l}\text { Autopista } \\
\text { Madrid-Toledo }\end{array}$ & 28.384 & 444.553 & 416.169 \\
\hline $\begin{array}{l}\text { AP-7 Cartagena - } \\
\text { Vera }\end{array}$ & Aucosta & 73.583 & 737.897 & 664.314 \\
\hline $\begin{array}{l}\text { AP-7 Circunvalación } \\
\text { de Alicante }\end{array}$ & Ciralsa & 26.101 & 443.395 & 417.295 \\
\hline $\begin{array}{l}\text { Total concesiones } \\
\text { consideradas }\end{array}$ & & 397.352 & 5.271 .822 & 4.874 .470 \\
\hline
\end{tabular}

Fuente: Delegación del Gobierno en las Sociedades Concesionarias de Autopistas Nacionales de Peaje.

Con independencia de si la opción finalmente elegida por el gobierno del Estado es la creación de una sociedad ad hoc o si opta por la solución que aquí hemos expuesto, hay una última consideración que debe tenerse en cuenta. Aunque, en el esquema teórico, se ha postulado que la CPP no podría dar cabida a los "elefantes blancos" 35 , los ejemplos de concesiones analizados en este artículo

35 Se acostumbran a designar así los proyectos de inversiones en infraestructuras públicas que carecen de una demanda social que los justifique en términos económicos, aunque sí pueden contar con otros elementos que avalen su legitimidad (la cohesión territorial, la viabilidad económica de determinadas zonas en regresión, etc). El origen de la expresión tiene que ver con determinadas tradiciones del sudeste asiático. 
plantean numerosas dudas respecto a que, en la práctica, no haya podido ser así. Si efectivamente se hubiese producido esta eventualidad, no hay otra alternativa para la viabilidad de esas concesiones concretas que la reasignación del riesgo de demanda, desplazándolo completamente al sector público, con un nuevo esquema retributivo del sector privado basado en la disponibilidad o bien, simplemente, con el "rescate" de la concesión y su operación desde el sector público como vías gratuitas. Creemos que ésta es la única salida, a largo plazo, de algunas de las vías analizadas aquí que registran, notoriamente, una menor demanda de uso.

\section{Reformas estructurales pendientes en el sistema concesional español}

Un funcionamiento eficiente, desde el punto de vista público, de las fórmulas contractuales de colaboración público-privada en la provisión de infraestructuras de interés público, debe contar, como requisito previo, con un marco de aplicación clara de los principios inspiradores del modelo. Esto es, la existencia de ganancias en la operación privada del servicio prestado por la infraestructura (value for money) y una repercusión "substancial" de los riesgos sobre el sector privado. El sistema legal español, como hemos visto, ha venido incorporando los criterios europeos en lo que respecta al carácter "substancial" del riesgo que deben asumir los operadores privados. Sin embargo, dicha incorporación ha tenido lugar más en el articulado de la legislación más general sobre la materia que en las medidas más vinculadas a la gestión concreta de las adjudicaciones. Esta práctica ha convertido en irrelevante la rigidez formal que presentan determinados aspectos de la legislación en este ámbito. En nuestra opinión esta situación ha perjudicado a la transparencia de esta modalidad contractual pública, tanto en lo que respecta a la percepción que tienen los ciudadanos de los objetivos de estas vinculaciones, como en lo que respecta a la eficiente asignación de riesgos y beneficios (utilidades) entre los ámbitos público y privado, lo cual es más preocupante en términos de la lógica del modelo. Por estas consideraciones, creemos que es fundamental proceder a algunos ajustes básicos en los elementos estructurantes del régimen legal concesionario español y, por extensión, del de la CPP.

En primer lugar, creemos que resulta imperativo substituir el principio de la "fuerza mayor" por el más amplio de "circunstancias impredecibles" en las afectaciones del riesgo de construcción que debe asumir el adjudicatario. Esto no sólo armonizaría el criterio del legislador con el de la jurisprudencia, como hemos visto, sino que además crearía un marco de mayores garantías para los inversores privados. No parece que la fórmula económica más eficiente de corrección de las mencionadas afectaciones sea la que difiere los importes correspondientes para su generación durante la operación de la infraestructura (abonados por el usuario o por la administración concedente), sino que se podría considerar la cre- 
ación de un marco permanente de garantías financieras de Estado basado en las instrumentadas específicamente para las autopistas que hemos visto en este artículo.

En segundo lugar, el concepto de reequilibrio económico debería abandonar el papel principal que asume en el actual sistema concesional español para desarrollar un papel más secundario, relacionado exclusivamente con determinadas decisiones de las Administraciones Públicas que afecten a posteriori las adjudicaciones. El objetivo de dicho desplazamiento sería eliminar, tanto como fuera posible, la práctica de las renegociaciones. Esto obligaría a crear un marco legal que permita un ajuste automático a los diversos avatares no previstos que una CPP, como contrato incompleto, atravesará durante su vigencia.

VASSALLO (2010), entre otros, ha propuesto con esta finalidad la implantación generalizada de la concesión de duración flexible (CDF). La CDF implica, básicamente, condicionar la duración de la CPP al logro de un determinado objetivo, pactado al inicio del contrato, para uno o más indicadores suficientemente representativos del retorno de la inversión privada (número de usuarios, ingresos...). En el momento en que dicho objetivo se alcanza, el contrato de CPP se da por concluido. Aunque este mecanismo reduce substancialmente el riesgo de demanda que asume el sector privado no lo elimina por completo, dado que al diferirse en el tiempo el retorno se incurre en mayores costes y menor rentabilidad. Así mismo, este mecanismo restringe los incentivos para la concurrencia, durante las licitaciones, de ofertas arriegadas con la esperanza de provocar renegociaciones oportunistas, en especial con sobrestimaciones de las cifras iniciales de usuarios.

No obstante, el sector de las empresas especializadas en este tipo de operaciones ha manifestado rotunda y reiteradamente su oposición a la implantación de la CDF como cláusula general. En el artículo citado, VASSALlo sintetiza en tres argumentos las razones de la oposición del sector privado:

a) La CDF no asegura, anualmente, los flujos de caja necesarios para hacer frente a los pagos comprometidos con los financiadores del proyecto.

b) Al no existir una clara referencia temporal de la duración, las tareas de operación y mantenimiento de la concesión se dificultan y encarecen innecesariamente.

c) El mecanismo no tiene un funcionamiento simétrico para el sector privado y el sector público, ya que sólo establece un límite máximo a la rentabilidad de la concesión, sin garantizar un mínimo. 
Como razona el mismo autor, se puede dar satisfacción a estas objeciones mediante la adición de correcciones específicas al modelo básico de CDF, la mayoría instrumentadas a través de mecanismos sobradamente conocidos en el mundo concesional. Se sugiere, así, que la resistencia a abandonar una práctica muy arraigada (la renegociación) tendría una estrecha relación con los pingües beneficios que los concesionarios han obtenido, en el pasado, con esta fórmula.

Una evolución del modelo básico de CDF es el que propone, por ejemplo, ANDreu ARASa (2012), combinando duración indeterminada de los contratos, valores actuales netos de los ingresos percibidos por un adjudicatario y subsidios en determinados casos de falta de demanda. El autor establece el contrato óptimo "por unos limites máximos y minimos de ingresos, determinados, por otra parte, de forma que el coste marginal del riesgo de los concesionarios sea igual al coste marginal de los subsidios" (p. 53). Así, la licitación de una concesión seguiría una fórmula de subasta de doble limite, donde las empresas concurrirían presentando el mínimo y el máximo valor descontado que estarían dispuestas a recibir, resultando adjudicataria la oferta con un menor valor ${ }^{36}$. "Si los ingresos del concesionario resultan menores del mínimo presentado en la licitación, la Administración pagaria la diferencia. Si los ingresos fueran superiores, la concesión terminaría y la Administración recibiría la diferencia de ingresos (en este caso no se pagaria subsidios). Finalmente, si los ingresos se situasen entre el techo y el suelo, el concesionario recibiría ingresos indefinidamente sin obtener ningún subsidio" (ANDREu ARASA, 2012: p. 53)

\section{GONGLUSIONES}

El colapso económico de algunas de las concesiones de autopistas de peaje españolas adjudicadas en el periodo 1998-2004 ha tenido como raíz la concepción, reiteradamente confirmada por la práctica de décadas, de la Administración concedente como fiable red de seguridad final de estas inversiones privadas en proyectos de interés público. La coincidencia de la recesión económica con el inicio de su puesta en servicio (a partir de 2008) agravó las dificultades inherentes a unas previsiones iniciales de usuarios sobreestimadas, que tenían como objetivo obtener la adjudicación y provocar, después, la renegociación oportunista de los términos. Al mismo tiempo, la crisis redujo, substancialmente, el margen de maniobra de la Administración del Estado para articular las soluciones efectivas,

\footnotetext{
${ }^{36} \mathrm{El}$ valor de las ofertas de ingresos se ponderaría mediante una función establecida por la Administración que incorporaría "el precio sombra de la financiación (el coste marginal del riesgo), el valor del parámetro que mide la ineficiencia de la Administración (el coste marginal del subsidio) y la función en la que se distribuye la demanda”.
} 
tanto a los desequlibrios económicos generados por la concurrencia de una casuística particularmente adversa a los proyectos como a los déficits de explotación.

La configuración de los principios de "riesgo y ventura" y "equilibrio económico" en la legislación española en materia concesional, combina elementos formales que refuerzan la idea de un notable desplazamiento de los riesgos al adjudicatario con otros que, desde las mismas disposiciones normativas, sirven de garantía a los intereses del concesionario ante las contingencias que puede atravesar la construcción y explotación de la concesión. Aunque en unos contratos de la especial naturaleza de los CPP, puede considerarse natural la búsqueda de un balance entre ambos conceptos, teniendo en cuenta que el nivel de riesgo efectivo de un proyecto de este tipo condiciona el atractivo para los posibles inversores, lo cierto es que el nivel general de protección del privado en el sistema legal español impide una eficiente la asignación del riesgo en los contratos de concesión, impedimentos que no han desaparecido completamente en la adaptación del derecho español a las directivas europeas sobre la materia.

El artículo plantea una solución pragmática al problema planteado por las concesiones en dificultades que pasa por al transferencia de estas a la SAREB y plantea una cuantificación restrictiva de las compensaciones a las concesionarias. Finalmente, se plantean algunas propuestas estructurales para aumentar la transparencia del sistema contractual de colaboración público-privada, en el cual se inscribe la figura de la concesión de obra pública, como vía principal de asegurar la deseable continuidad y operatividad de este sistema.

\section{BIBLIOGRAFÍA}

ANDREu ARASA, Jorge: "Las colaboraciones público privadas. Gestión eficiente de los riesgos", Boletín Económico del ICE, núm. 3032, 2012, pp. 45-54.

Arimany Lamoglia, Esteban: "El equilibrio económico financiero de la concesión de obra pública: a propósito de la sentencia del Tribunal Supremo «Autopista Madrid-Toledo (AP-41)»", Actualidad jurídica Uría Menéndez, Madrid, núm. Especial, 2011, pp.93-100.

Athias, Laure y Soubeyran, Raphael: Demand Risk Allocation in Incomplete Contracts: The Case of Public Private Partnerships, Working Paper, 2012.

Baeza Muñoz, Maria de los Ángeles: Planificación económico-financiera de las concesiones de autopistas de peaje. Un estudio empírico del caso español, Universidad de Granada (Tesis doctoral), 2008, 277 pp. 
Baeza, María de los Ángeles y Vassallo, José Manuel: "La intervención de la Administración ante las dificultades financieras de las sociedades concesionarias de autopistas de peaje", Presupuesto y Gasto Público, Instituto de Estudios Fiscales, Madrid, núm. 65, 2011, pp. 51-60

BAIN, Robert: "Error and optimism bias in toll road traffic forecasts", Transportation, febrero 2009.

BEL, GERMÀ: "La racionalización de las infraestructuras de transporte en España", Cuadernos Económicos de ICE, núm. 80, 2010, pp. 211-228.

BeL, Germà y FAgedA, Xavier: "Is a mixed funding model for the highway network sustainable over time? The Spanish case", Research in Transportation Economics, num. 15, 2005, pp.187-203.

Gantos Sánchez, Pedro y Álvarez San-Jaime, Óscar: "El valor del tiempo con congestión: el caso de la Radial-3", Revista de Economía Aplicada, núm. 51 (vol. XVII), 2009, pp 55-80.

Consejo Europeo: Propuesta de Directiva del Parlamento Europeo y del Consejo relativa a la adjudicación de contratos de concesión. Bruselas, COM(2011) 897 final 2011/0437.

Delegación del Gobierno en las Sociedades Concesionarias de AutopisTAS Nacionales DE PEaje: Informe 2011 sobre el sector de autopistas de peaje en España, Ministerio de Fomento, Madrid, 2013, 213 pp.

Engel, Eduardo, Fischer, Ronald, Galetovic, Alexander y Hermosilla, Manuel: "Renegociaciones de concesiones en Chile", Estudios Públicos, núm. 113, 2009, 151-205.

Eurostat: Manual on Government Deficit and Debt. Implementation of ESA95, European Union, Luxemburg, 2010, 352 pp.

González-Savignat, Mar, Matas, Anna i Raymond, Josep Lluis: "La predicción de la demanda en evaluación de proyectos". Cuadernos económicos de ICE, núm. 80, 2010, pp. 189-211.

Guasch, José Luis: Concesiones en infraestructura. Cómo hacerlo bien, Antoni Bosch Editor, Barcelona, 2005, 240 pp. [Traducción al castellano de Granting and Renegotiating Infrastructure Concessions: Doing It Right, WBI Development Studies. World Bank, Washington, D.C, 2004.] 
IZQUIERDO, Rafael y VASSALLO, José Manuel: Estudio sobre los contratos de concesión de obras públicas, Comisión de Economía de las Obras Públicas del Colegio de Ingenieros de Caminos Canáles y Puertos, Madrid, 2002, 104 pp.

Puerto Cela, Mariano: "Aspectos presupuestarios de la colaboración públicoprivada", Presupuesto y Gasto Público, Instituto de Estudios Fiscales, núm. 45, Madrid, 2006, pp.95-103.

SÁnchez Soliño, Antonio: "Optimización de la transferencia de riesgos en los Contratos de Infraestructuras y Servicios Públicos”, Hacienda Pública Española / Review of Public Economics, núm. 201, 2012, pp. 67-91

Secretaria de Estado de Infraestructuras, Transportes y Vivienda: El tráfico en las autopistas de peaje 2011, Ministerio de Fomento, Madrid, 2012, 420 pp.

Vassallo, José Manuel: "Flexible-Term Highway Concessions. How Can They Work Better?", Transportation Research Record: Fournal of the Transportation Research Board, Washington, núm. 2187, 2010, pp. 22-28. 